\title{
The roles of "face" and "non-face" areas during individual face perception: Evidence by fMRI adaptation in a brain-damaged prosopagnosic patient
}

Citation for published version (APA):

Dricot, L., Sorger, B., Schiltz, C., Goebel, R. W., \& Rossion, B. (2008). The roles of "face" and "non-face" areas during individual face perception: Evidence by fMRI adaptation in a brain-damaged prosopagnosic patient. Neuroimage, 40(1), 318-332. https://doi.org/10.1016/j.neuroimage.2007.11.012

Document status and date:

Published: 01/01/2008

DOI:

10.1016/j.neuroimage.2007.11.012

Document Version:

Publisher's PDF, also known as Version of record

Document license:

Taverne

Please check the document version of this publication:

- A submitted manuscript is the version of the article upon submission and before peer-review. There can be important differences between the submitted version and the official published version of record.

People interested in the research are advised to contact the author for the final version of the publication, or visit the DOI to the publisher's website.

- The final author version and the galley proof are versions of the publication after peer review.

- The final published version features the final layout of the paper including the volume, issue and page numbers.

Link to publication

\footnotetext{
General rights rights.

- You may freely distribute the URL identifying the publication in the public portal. please follow below link for the End User Agreement:

www.umlib.nl/taverne-license

Take down policy

If you believe that this document breaches copyright please contact us at:

repository@maastrichtuniversity.nl

providing details and we will investigate your claim.
}

Copyright and moral rights for the publications made accessible in the public portal are retained by the authors and/or other copyright owners and it is a condition of accessing publications that users recognise and abide by the legal requirements associated with these

- Users may download and print one copy of any publication from the public portal for the purpose of private study or research.

- You may not further distribute the material or use it for any profit-making activity or commercial gain

If the publication is distributed under the terms of Article 25fa of the Dutch Copyright Act, indicated by the "Taverne" license above, 


\title{
The roles of "face" and "non-face" areas during individual face perception: Evidence by fMRI adaptation in a brain-damaged prosopagnosic patient
}

\author{
Laurence Dricot, ${ }^{\mathrm{a}, *}$ Bettina Sorger, ${ }^{\mathrm{b}, \mathrm{c}}$ Christine Schiltz, ${ }^{\mathrm{a}}$ Rainer Goebel, ${ }^{\mathrm{b}, \mathrm{c}}$ and Bruno Rossion ${ }^{\mathrm{a}, \mathrm{d}, *}$

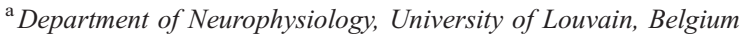 \\ ${ }^{\mathrm{b}}$ Department of Cognitive Neuroscience, Maastricht University, The Netherlands \\ ${ }^{\mathrm{c}}$ Maastricht Brain Imaging Center (M-BIC), Maastricht, The Netherlands \\ ${ }^{\mathrm{d}}$ Department of Cognitive Development, University of Louvain, Belgium
}

Received 1 May 2007; revised 5 November 2007; accepted 7 November 2007

Available online 22 November 2007

Two regions in the human occipito-temporal cortex respond preferentially to faces: 'the fusiform face area' ('FFA') and the 'occipital face area' ('OFA'). Whether these areas have a dominant or exclusive role in face perception, or if sub-maximal responses in other visual areas such as the lateral occipital complex (LOC) are also involved, is currently debated. To shed light on this issue, we tested normal participants and PS, a well-known brain-damaged patient presenting a face-selective perception deficit (prosopagnosia) [Rossion, B., Caldara, R., Seghier, M., Schuller, A. M., Lazeyras, F., Mayer, E. (2003). A network of occipito-temporal face-sensitive areas besides the right middle fusiform gyrus is necessary for normal face processing. Brain 126 2381-2395.], with functional magnetic resonance imaging (fMRI). Of particular interest, the right hemisphere lesion of the patient PS encompasses the 'OFA' but preserves the 'FFA' and LOC [Sorger, B., Goebel, R., Schiltz, C., Rossion, B. (2007). Understanding the functional neuroanatomy of acquired prosopagnosia. NeuroImage 35, 836-852.]. Using fMRI-adaptation, we found a dissociation between the coding of individual exemplars in the structurally intact 'FFA', which was impaired for faces but preserved for objects in the patient PS's brain. Most importantly, a larger response to different faces than repeated faces was found in the ventral part of the LOC both for normals and the patient, next to the right hemisphere lesion. Thus, following prosopagnosia, areas that do not respond preferentially to faces such as the ventral part of the LOC (vLOC) may still be recruited for compensatory or residual individual face perception. Overall, these observations indicate that several highlevel visual areas in the human brain contribute to individual face

\footnotetext{
* Corresponding authors. L. Dricot is to be contacted at Laboratoire de Neurophysiologie, Université catholique de Louvain, Avenue Hippocrate, 54, 1200 Bruxelles, Belgium, fax: +32276454 49. B. Rossion, Faculté de Psychologie, Université catholique de Louvain, 10, Place Cardinal Mercier, 1348 Louvain-la-Neuve, Belgium, fax: +32 10473774.

E-mail addresses: laurence.dricot@uclouvain.be (L. Dricot), bruno.rossion@uclouvain.be (B. Rossion).

Available online on ScienceDirect (www.sciencedirect.com).
}

perception. However, a subset of these areas in the right hemisphere, those responding preferentially to faces ('FFA' and 'OFA'), appear to be critical for this function.

(C) 2007 Published by Elsevier Inc.

\section{Introduction}

Functional neuroimaging studies of the human visual cortex have identified several areas that play an important role in object perception and recognition (Grill-Spector and Malach, 2004). These regions respond more strongly when viewing pictures of object shapes than control stimuli preserving low-level visual information such as textures, visual noise, or scrambled objects. Among these areas, the lateral occipital cortex (LOC; e.g. GrillSpector et al., 2001; Grill-Spector et al., 1999; Grill-Spector et al., 1998; Malach et al., 1995) shows greater fMRI response to objects (including faces) than these control stimuli, but this area does not show systematic larger responses to some object categories than others. It is located anterior to retinotopic visual areas, extending both ventrally (vLOC) on the lateral bank of the fusiform gyrus and dorsally (dLOC) in two anatomically segregated subregions. Anterior to the $\mathrm{vLOC}$, a region of the lateral fusiform gyrus, the 'fusiform face area', or 'FFA' (e.g. Kanwisher et al., 1997; Sergent et al., 1992) also responds more strongly to objects than control stimuli, but shows a preferential response for faces above all other object categories. Larger responses to faces than objects are also consistently observed in the inferior occipital gyrus, the so-called 'occipital face area' ('OFA'; Gauthier et al., $2000 \mathrm{~b}$ ) generally posterior to, and partially overlapping with the vLOC.

FMRI-adaptation (Grill-Spector et al., 2006a; Grill-Spector and Malach, 2001) or repetition-suppression (Henson and Rugg, 2003) studies show a larger response in the LOC to novel objects 
than to repeated objects (Avidan et al., 2002; Grill-Spector et al., 1999; Sayres and Grill-Spector, 2006) and a correlation of that response with recognition performance (Avidan et al., 2002; Bar et al., 2001; Grill-Spector et al., 2000; James et al., 2000). Similar effects have been observed in both the 'FFA' and 'OFA' for faces (e.g. Eger et al., 2004b; Gauthier et al., 2000b; GilaieDotan and Malach, 2007; Grill-Spector et al., 2004; Loffler et al., 2005; Rotshtein et al., 2005; Schiltz and Rossion, 2006). These observations indicate that the LOC and both of the 'face areas' are directly involved in the perception of individual exemplars of objects and faces respectively.

An unresolved issue is whether a high-level visual area that does not respond preferentially to one category, i.e. the LOC for faces, nevertheless plays a role in discriminating individual members of that category. According to a strict localizationist view, the answer to this question is negative. This view suggests a dominant or exclusive role of areas responding preferentially to faces, such as the 'FFA', for face perception (Kanwisher et al., 1997; Kleinschmidt and Cohen, 2006; Spiridon and Kanwisher, 2002). In contrast, according to a more distributed view, a large part of the ventral stream, including the 'FFA', contributes to face perception (Haxby et al., 2001; Tovee, 1998). That is, visual areas that do not respond preferentially to faces, such as the LOC, would also play a role in face perception. Moreover, areas responding preferentially to faces, such as the 'FFA', would also contribute to object perception.

Here we aimed to shed light on this issue by recording fMRIadaptation in a well described brain-damaged patient, PS, who is no longer able to perceive and recognize individual faces, i.e. acquired prosopagnosia (Bodamer, 1947; Quaglino et al., 2003; Sergent and Signoret, 1992). Contrary to most cases of prosopagnosia, the patient's ability to recognize and discriminate non-face objects, even at the individual level, is remarkably preserved (Rossion et al., 2003; Schiltz et al., 2006). Her prosopagnosia follows a dominant right hemispheric lesion in the inferior occipital cortex, which damaged the territory of the right 'OFA', where no face preferential activation can be observed. Despite this lesion, the patient has a right 'FFA' as significant and large in size as in normal controls (Rossion et al., 2003; Sorger et al., 2007), a finding that has also been reported in another braindamaged case of prosopagnosia with bilateral inferior occipital lesions encompassing the 'OFA' (Steeves et al., 2006). However, there is a lack of release from identity adaptation to individual faces in the patient PS's right 'FFA', in agreement with her behavioral impairment at discriminating individual faces (Schiltz et al., 2006). Most recently, we have mapped the low- and high-level visual areas of the patient PS with respect to her lesions, and observed a right vLOC area of equal size and level of activation than normals, next to the dominant lesion causing prosopagnosia (Sorger et al., 2007).

In the present study, we took advantage of this pattern of structurally damaged (right 'OFA') and intact (right 'FFA' and LOC) tissue in PS's brain to test two hypotheses.

First, we asked whether the patient's 'FFA', which does not show release from adaptation to face identity (Schiltz et al., 2006), may nevertheless play a role in her preserved ability to discriminate individual exemplars of objects. To do that, we used an experiment in which all normal participants showed release from identity adaptation to both objects and faces in the 'FFA', and tested it in the same area in the patient's brain. We found for the first time that release from adaptation was significant for objects in both normal viewers and the patient's 'FFA', still in the absence of any effect for faces for the patient.

Second, a whole-brain analysis of the patient's data in the same experiment revealed a significant release from adaptation to individual exemplars of faces in the right vLOC only, an area that does not respond stronger to faces than objects. More specifically, both objects and faces showed release from adaptation effects in all normal participants, and in the patient's brain, in the right vLOC. These results suggest that following brain damage, the prosopagnosic patient is unable to recruit her dominant face perception system in the 'FFA' to discriminate individual faces, but rather relies on an area that does not respond preferentially to faces. This is in line with her performances during individual face discrimination tasks, which are seriously deficient, but yet largely above chance level.

These observations were tested further in two fMRI experiments using an event-related paradigm. In experiment 2, pictures of faces and objects were used by pairs and showed the same results as in the block design used in experiment 1 . In the third experiment, an active discrimination of facial identity was performed.

\section{Materials and methods}

\section{Subjects}

The prosopagnosic patient PS has already been described in detail in previous studies (Caldara et al., 2005; Rossion et al., 2003; Schiltz et al., 2006; Sorger et al., 2007). Briefly, PS was born in 1950 and sustained a closed head injury in 1992 that left her with extensive lesions of the left mid-ventral (mainly fusiform gyrus) and the right inferior occipital cortex. Minor damages to the left posterior cerebellum and the right middle temporal gyrus were also detected (see Sorger et al., 2007 for all information about the patient's lesions). After medical treatment and neuropsychological rehabilitation, PS recovered extremely well from her cognitive deficits following the accident. Her only continuing complaint remains a profound difficulty in recognizing familiar faces, including those of her family when they are presented out of context. To determine a person's identity, she relies on external (non-face-inherent) cues such as haircut, moustache or glasses, but also on the person's voice, posture, gait, etc. She may also use suboptimal facial cues such as the mouth or the external contour of the face to recognize faces, and is particularly impaired at extracting diagnostic information from the eyes of the face (Caldara et al., 2005). Effectively, PS is like normal subjects (100\%, fast) to discriminate faces from other objects but is impaired and slowed down to recognize faces at the individual level (Schiltz et al., 2006). The Benton Face Recognition Test (BFRT) (Benton and Van Allen, 1972) ranks her as highly impaired, and her score at the Warrington Recognition Memory Test (WRMT) (Warrington, 1984) for faces characterizes her as significantly less accurate as controls (see Table 1 in Rossion et al., 2003). PS does not present any difficulty in recognizing objects, even at the subordinate level (Rossion et al., 2003; Schiltz et al., 2006). Her visual field is almost full (small left paracentral scotoma) and her visual acuity is good ( 0.8 for both eyes as tested in August 2003). As indicated in the Introduction section, in our previous neuroimaging studies of the patient PS, we found that she had a right 'FFA' as significant and large in size as normal controls (Rossion et al., 2003; Schiltz et al., 2006) in the absence of a right 'OFA' or left 'FFA' (damaged, 
see Sorger et al., 2007). However, there was a lack of release from face adaptation to faces in the patient's right 'FFA' (Schiltz et al., 2006). Our more recent investigations have identified a right vLOC area of equal size and level of activation than normals (see Sorger et al., 2007).

In the present study, besides PS, a group of five control subjects (S2 to S6, age range 25 to 35,3 females), 3 subjects (S5, S8, S11; age range 25 to 35,3 females), and six subjects (S5 to S10, age range 25 to 35,3 females) performed the same localizers, and respectively the block design experiment 1 , the event-related experiments 2 and 3 of the present study. In addition, one agematched (S1, 54 years, female) performed the localizers and the experiments 1 and 2. We tested only one age-matched control to PS because the profile of activation in the right middle fusiform gyrus remains stable across decades (Brodtmann et al., 2003) and our previous studies have shown identical face and object differential responses, as well as adaptation effects to faces in the 'FFA' for 3 age-matched controls and younger controls (Schiltz et al., 2006; Sorger et al., 2007). Similarly, the profile of neural response in the present fMRI experiments was not different for the age-matched control and the young controls in the areas of interest.

PS and the control subjects gave their informed written consent prior to the fMRI experiments. The study was conformed to the Declaration of Helsinki and was approved by the Ethics Committee of the Medical Department of the University of Louvain. All subjects and PS proved to be strongly right-handed according to the Edinburgh Inventory (Oldfield, 1971).

\section{Stimuli and procedures}

\section{Localizers}

PS and normal controls performed two block-design localizer fMRI experiments aimed at defining the areas responding preferentially to faces ('FFA' and 'OFA'), and to objects (vLOC and dLOC). In the face localizer experiment, PS and controls viewed 8 blocks per run ( $36 \mathrm{~s}$ per block, two runs of 6 min $42 \mathrm{~s}$ ) of alternating pictures of faces and objects, with $12 \mathrm{~s}$ fixation cross epochs between the blocks. They performed a one-back identity task (two positives per block). 36 stimuli were presented for $800 \mathrm{~ms}$ followed by a $200 \mathrm{~ms}$ blank screen during each block. All images (pictures of faces and objects) were presented in color and sustained a size of roughly $4^{\circ}$ of visual angle. They were matched for mean luminosity and varied location in X $(10 \%)$ and in Y $(13 \%)$ on each trial. Faces (half male) were cropped so that no external features (hair, etc.) were present. PS and normal controls were also scanned during an independent LOC localizer (Sorger et al., 2007). In the LOC localizer experiment, participants viewed 6 blocks per run ( 30 s per block, two runs of $5 \mathrm{~min} 20 \mathrm{~s}$ ) of alternating pictures of common objects from different object categories and scrambled objects, with 20 s fixation cross epochs between the blocks. 44 black and white photographs per block $(252 \times 252$ pixel gray-scale images $)$ were foveally presented during $666 \mathrm{~ms}$ per object or scrambled object. The scrambling was realized by tessellating the objects photos into squares of $10 \times 10$ pixels. Participants simply had to fixate attentively the visual stimulation.

\section{Experiment 1: block design adaptation with faces and objects}

In the first experimental runs, an fMRI-adaptation paradigm (block design) was used in a $2 \times 2$ factorial design: repetition (identical or different pictures in a block) $\times$ category (faces or butterflies) (Fig. 1). We used pictures of butterflies as our object

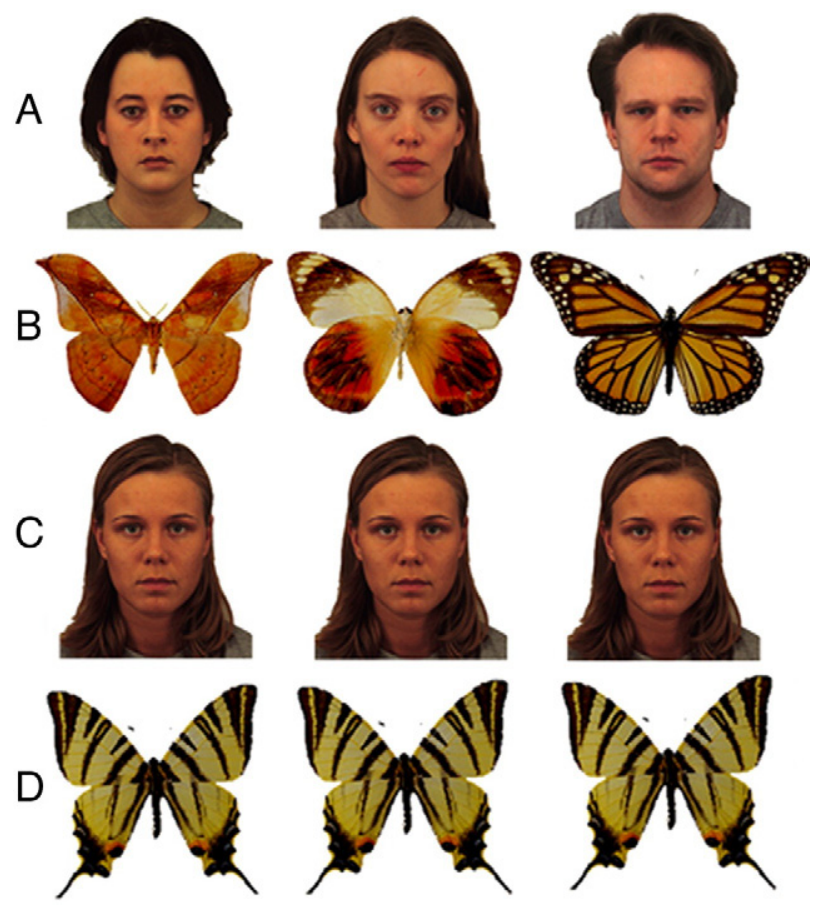

Fig. 1. Examples of pictures of faces and butterflies used in the block design fMRI experiment 1. Four conditions were presented to PS and control subjects: blocks with A different faces; (B) different butterflies; (C) identical faces; (D) identical butterflies. All images were presented in color and sustained a size of roughly $4^{\circ}$ of visual angle.

category because they showed robust 'FFA' activation in pilot experiments and strong adaptation effects in all our normal participants in this area. In our previous study using a $1.5 \mathrm{~T}$ scanner, we found significant release from adaptation for pictures of cars in the 'FFA' in a group analysis, but it was not significant for every single control subjects, and for the patient PS (who did not differ significantly from controls as a group; Schiltz et al., 2006). In the event-related experiment with pictures of chairs, there was no significant release from adaptation, neither for controls and the patient (Schiltz et al., 2006). Here, besides using a more sensitive methodology, we selected an object category for which exemplars were highly different in shape, texture and color (Fig. 1), in order to maximize our chances to observe significant release from adaptation in the 'FFA' of every single normal participant. Similarly, face stimuli were presented in color, with external features (hairstyle, etc.), unlike the cropped grayscale faces used in our previous study (Schiltz et al., 2006), both to test the robustness of our previous results and to ensure significant effects in every normal participant, even in areas which do not respond preferentially to faces. Note that the degree of similarity between two members of the object category and the face category was not meant to be equal. In fact, when color is not considered, the mean inter-pixel correlation computed for faces and butterflies separately was slightly higher for pictures of butterflies than faces ( 0.59 vs. $0.57 ; p<0.01)$. Note that if color is considered, pictures of butterflies may appear more dissimilar than pictures of individual faces (Fig. 1), but our goal here was to compare differential adaptation effects between the patient and the normals for the two categories, not to compare directly the adaptation for the two types of stimuli (see discussion of this issue in Discussion section). 
The subject's task was to indicate the rare occurrence of a face or a butterfly picture that appeared colorized in red, in a block of normally colorized stimuli (color detection task). We used a task that is orthogonal to the variable manipulated (repetition), as done previously (Gauthier et al., 2000a; Rotshtein et al., 2005; Schiltz et al., 2006; Winston et al., 2004), to ensure that subjects were paying attention during the whole experiment, while performing at the same level for all conditions. It is also a task that the patient PS can perform easily, so that any activation difference between PS and the controls cannot be attributed to task difficulty (Price and Friston, 1999).

We presented 8 alternating blocks per run (36 s per block, 4 runs of 6 min $42 \mathrm{~s}$ ) of pictures of faces and butterflies: two blocks with 36 identical faces or butterflies and two blocks with 36 different faces or butterflies. 36 stimuli were presented for $800 \mathrm{~ms}$ followed by a $200 \mathrm{~ms}$ blank screen during each block. Stimuli were displayed in pseudo-random order. All images (pictures of faces and butterflies, Fig. 1) were presented in color, and sustained a size of roughly $4^{\circ}$ of visual angle.

Experiment 2: event-related paradigm with faces and objects

Participants viewed three runs of 80 pairs of stimuli. The stimuli were pictures of faces and butterflies as shown in Fig. 1. Thirty-eight face images and 42 butterfly pictures were used in an event-related design. There were 4 conditions of interest: two different face identities, two identical face identities, two different butterflies, two identical butterflies in the pair. A fifth condition of a butterfly followed by a face image (or the opposite order for half of the trials) was used. Participants were asked to press the response key only for this latter condition - that is, to detect faceobject pair trials. This basic-level discrimination task ensured that the participants were paying attention to the stimuli, and it was again a task that PS could perform well. Further, the factors of interest of the study (category effect: faces vs. butterflies; adapt- ation effect: same vs. different identities) would not be contaminated by any decisional and/or motor processes since the behavioral task was completely orthogonal to these factors. Hence, any difference between normals and PS could not be attributed to general processing difficulties on the trials of interest. There were 16 trials/condition/run, for a total of 80 trials in each run, and 48 trials/condition over three runs. The order of conditions was fully randomized within a run. Within a trial, the first stimulus of a pair was presented for $1000 \mathrm{~ms}$ following by a blank of $500 \mathrm{~ms}$ and thereafter by the second stimulus of the pair, which was presented for $1000 \mathrm{~ms}$. The pairs were separated by a fixation cross with a duration 5000,6250 or $7500 \mathrm{~ms}$ (4-6 TRs), and these interstimulus interval (ISI) durations were also fully randomized. This timing ensured that the onset of distinct events were separated by at least 6-8 TRs (7500-10,000 ms) to avoid the overlapping of hemodynamic responses. Randomization of trial order and of ISI duration further reduced any potential top-down effects of anticipation of the stimuli.

Experiment 3: event-related paradigm during face discrimination

To test further the patient's residual individual face discrimination abilities while monitoring brain activation, we tested PS and normal participants in an event-related paradigm during an active individual face discrimination task. In this experiment, PS and control subjects viewed three runs ( 8 min 57 s 500 ms per run) of 60 pairs of faces. The first face of the pair was presented during $1000 \mathrm{~ms}$ following by a blank of $500 \mathrm{~ms}$ and thereafter by the second face of the pair. The pairs were separated by a fixation cross during 5000, 6250 or $7500 \mathrm{~ms}$. The subject had to determine whether the 2 faces were the same person (identical image) or not. All the faces (half male) were shown on frontal view and were cropped so that no external features (hair, etc.) were revealed (Fig. 8A). All the faces were presented in color.

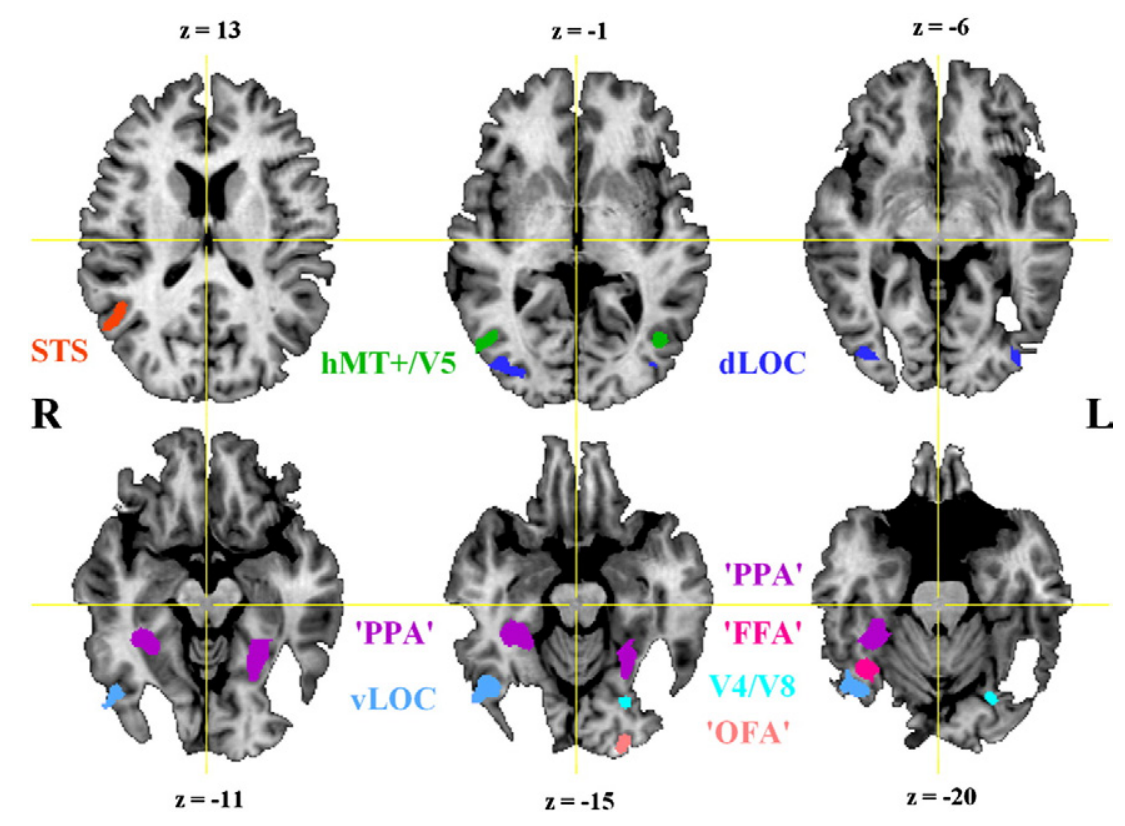

Fig. 2. Functional areas of the patient PS on segmented brain slices. 'FFA': 'fusiform face area', area responding more to faces than objects in the right fusiform gyrus; 'OFA': 'occipital face area', area responding more to faces than objects in the left inferior occipital gyrus; dLOC and vLOC: dorsal and ventral part of the lateral occipital complex, area responding more to objects than scrambled objects; STS: area of the superior temporal sulcus responding more to faces than objects; hMT+/V5: motion area; 'PPA', 'Parahippocampal Place Area', area responding more to pictures of scenes than faces and objects; V4/V8: color area (for functional localization methods, see Sorger et al., 2007). 
For all 3 experiments, the stimuli were jittered in location by 40 pixels in $\mathrm{X}\left(5 \%, 1.2^{\circ}\right.$ visual angle $)$ and 40 pixels in $\mathrm{Y}\left(7 \%, 1.2^{\circ}\right)$ from trial-to-trial to avoid that the same pixels would be repeated at the same position in the conditions of adaptation. Stimuli (and blocks) were displayed with a PC running E-prime 1.1 (PST Inc.) through a projector surface located over the head of the subject and viewed with an angled mirror.

\section{Imaging parameters}

MR images of brain activity were collected from PS and normal controls using a 3T head scanner (Siemens Allegra, Siemens AG, Erlangen, Germany), with repeated single-shot echo-planar imaging: echo time $(\mathrm{TE})=50 \mathrm{~ms}$, flip angle $(\mathrm{FA})=90^{\circ}$, matrix size $=64 \times 64$, field of view $(\mathrm{FOV})=224 \times 224 \mathrm{~mm}^{2}$, slice order descending and interleaved, slice thickness $=3.5 \mathrm{~mm}$. The other scan parameters varied over the different experiments: repetition time $(\mathrm{TR})=1500 \mathrm{~ms}, 24$ slices, run time $=6 \mathrm{~min} 42 \mathrm{~s}$ for the 'FFA' localizer and the block experiment $1 ; \mathrm{TR}=2000 \mathrm{~ms}, 24$ slices, run time $=5 \mathrm{~min} 20 \mathrm{~s}$ for the vLOC localizer; and TR=1250 ms, 21 slices, for the event-related experiments $(2$ : run time $=11 \mathrm{~min} 46 \mathrm{~s}$ $250 \mathrm{~ms}$, and 3: run time $=8 \mathrm{~min} 57 \mathrm{~s} 500 \mathrm{~ms}$ ). A three-dimensional (3D) T1-weighted data set encompassing the whole brain was acquired to provide detailed anatomy $\left(1 \mathrm{~mm}^{3}\right)$ thanks to a "Modified Driven Equilibrium Fourier Transform" (MDEFT) sequence (scan parameters: $\mathrm{TR}=7.92 \mathrm{~ms}, \mathrm{TE}=2.4 \mathrm{~ms}, \mathrm{FA}=15^{\circ}$, matrix size $=256 \times 256$, FOV $=256 \times 256 \mathrm{~mm}^{2}, 176$ slices, slice thickness $=1 \mathrm{~mm}$, no gap, total scan time $=13 \mathrm{~min}$ and $43 \mathrm{~s}$ ).

\section{Data analysis of the imaging experiments}

The fMRI signal in the different conditions was compared using Brain Voyager QX (Version 1.4, Brain Innovation, Maastricht, The Netherlands). Prior to analysis, the functional data sets were subjected to a series of preprocessing operations. Preprocessing consisted of a linear trend removal for excluding scanner-related signal, a temporal high-pass filtering applied to remove temporal frequencies lower than 3 cycles per run, and a correction for small interscan head movements by a rigid body algorithm rotating and translating each functional volume in $3 \mathrm{D}$ space. In addition, the data from the event-related experiment were also corrected for the difference between the scan times of the 21 slices. Data was not smoothed in the spatial domain for any of the experiments. In order to be able to compare the locations of activated brain region across subjects all anatomical as well as the functional volumes were spatially normalized (Talairach-transformation; Talairach and Tournoux, 1988) and the statistical maps computed were overlaid to the 3D T1-weighted scans in view to calculate Talairach coordinates for all relevant activation clusters. Subsequently, the functional data were analyzed using multiple regression models (General Linear Model; GLM) consisting of predictors, which corresponded to the particular experimental conditions of each experiment. The predictor time courses used were computed on the basis of a linear model of the relation between neural activity and hemodynamic response, assuming a rectangular neural response during phases of visual stimulation (Boynton et al., 1996).

The areas responding preferentially to faces were first defined independently for PS and each individual subject using the localizer experiment. In order to localize the 'FFA' and the 'OFA', the conjunction of the contrast (faces vs. objects) between the two runs was computed. This procedure ensured that larger activations to faces than objects identified were those consistent across the two runs. A similar procedure was applied to disclose LOC voxels with the contrast (objects vs. objects scrambled) in the LOC localizer. All contiguous voxels in the right 'FFA' and the right 'OFA' significant at $t>5.59$ [one-tailed, $p$ (Bonferroni corrected for multiple comparison $<0.002]$ were considered for further analysis. When foci of activations were too large so that fusiform and inferior occipital activation foci overlapped, the statistical threshold was raised to a more conservative value [one-tailed, $p$ (Bonf) $<$ $0.0001]$ to separate the two functional regions spatially (see Table 1). For the ventral part of the LOC, all contiguous voxels significant at $t>5.6$ [one-tailed, $p$ (Bonf) $<0.002$ ] or a more conservative threshold when necessary (i.e. if there was an overlap between vLOC and dLOC) were considered for further analysis. For two subjects, a threshold of $t>3.6$ or 4.6 [ $q$ (False Discovery Rate $<0.05$ ] was used due to the smaller size of their vLOC. All information about the regions of interest and thresholds for each individual subject is provided in Table 1 .

Second, the above-defined regions of interest (ROIs) were tested for fMRI-adaptation to identity in the block design with repeated-measures ANOVA using the contrast (different vs. same) for each category. The interaction between the fMRI-adaptation to butterfly and to faces was computed by the contrast: [(faces different-faces repeated)-(butterflies different-butterflies repeated)]. A random effect analysis to test these effects across subjects was also performed by running a multi-subject GLM with predictors separated for each included control subject. FMRI signals averaged over each subject's ROIs were also extracted and percent signal change was computed using the baseline epochs as reference for each condition. An adaptation index [(different - same)/ (different+same)] allowing a comparison between PS and the control group was computed for each category using the beta weights of the GLM analysis.

For the event-related experiment 2, an identical analysis was performed to test the fMRI-adaptation to individual faces and objects in the ROIs. In experiment 3, we used a GLM analysis with the contrast (different faces vs. same faces). Correct trials only were included in the analyses. We also extracted the averaged fMRI signals and computed a Faces Index adaptation as in the other experiments.

\section{Results}

In the face localizer, there was a significantly larger response to faces compared to objects in the right middle fusiform gyrus ('FFA') for all control subjects (Talairach coordinates: $36 \pm 4,-48 \pm 6$, $-15 \pm 4$; mean cluster size: 717 voxels \pm 491$)$ and for PS $(35,-53$, $-20 ; 479$ voxels) (Table 1$)$. In the object localizer, there was a significantly larger response to objects compared to scrambled objects with an activation corresponding to the ventral part of the right occipital complex (vLOC) for both controls (Talairach coordinates: $41 \pm 5,-65 \pm 9,-11 \pm 4$; mean cluster size: 385 voxels \pm 228$)$ and PS (43, $-64,-12 ; 632$ voxels) (Table 1$)$. In addition, the right 'OFA' for each control was defined: (Talairach coordinates: $34 \pm 5,-71 \pm 6,-14 \pm 4$; mean cluster size: 756 voxels \pm 833 ) (Table 1).

\section{FMRI-adaptation to faces and objects (block-design experiment)}

PS and control subjects performed the color detection task at ceiling in all conditions (mean $=99.5 \pm 0.4 \%$ ), without any 
Table 1

Talairach locations, $t$-values and cluster sizes of the functionally defined regions of interests (right-sided 'FFA', 'OFA' and vLOC) defined in the localizer experiments for the patient PS and the control subjects

\begin{tabular}{|c|c|c|c|c|c|c|}
\hline \multirow[t]{2}{*}{ Subject } & \multirow[t]{2}{*}{ Region } & \multicolumn{3}{|c|}{ Talairach coordinates } & \multirow[t]{2}{*}{$t$} & \multirow{2}{*}{$\begin{array}{l}\text { Cluster } \\
\text { size } \\
\left(\mathrm{mm}^{3}\right)\end{array}$} \\
\hline & & $x$ & $y$ & $z$ & & \\
\hline \multirow{3}{*}{ PS } & 'FFA' & 35 & -53 & -20 & 5.59 & 479 \\
\hline & 'OFA' & Lesioned & & & & \\
\hline & vLOC & 43 & -64 & -12 & 6 & 632 \\
\hline \multirow[t]{3}{*}{ S1 } & 'FFA' & 31 & -56 & -12 & 5.59 & 479 \\
\hline & 'OFA' & 36 & -85 & -8 & 5.59 & 1116 \\
\hline & vLOC & 35 & -65 & -7 & 6 & 798 \\
\hline \multirow[t]{3}{*}{ S2 } & 'FFA' & 43 & -57 & -13 & 5.59 & 772 \\
\hline & 'OFA' & 31 & -73 & -18 & 5.59 & 492 \\
\hline & vLOC & 46 & -66 & -14 & 4.6 & $44^{*}$ \\
\hline \multirow[t]{3}{*}{ S3 } & 'FFA' & 34 & -48 & -11 & 7.6 & 281 \\
\hline & 'OFA' & 37 & -66 & -15 & 7.6 & 1996 \\
\hline & vLOC & 46 & -70 & -9 & 6 & 493 \\
\hline \multirow[t]{3}{*}{ S4 } & 'FFA' & 32 & -40 & -19 & 5.59 & 608 \\
\hline & 'OFA' & 34 & -61 & -14 & 5.59 & 573 \\
\hline & vLOC & 41 & -72 & -8 & 6 & 538 \\
\hline \multirow[t]{3}{*}{ S5 } & 'FFA' & 37 & -41 & -16 & 5.59 & 1410 \\
\hline & 'OFA' & 36 & -68 & -16 & 5.59 & 2545 \\
\hline & vLOC & 38 & -73 & -9 & 7 & 245 \\
\hline \multirow[t]{3}{*}{ S6 } & 'FFA' & 39 & -44 & -16 & 8 & 526 \\
\hline & 'OFA' & 39 & -70 & -19 & 8 & 253 \\
\hline & vLOC & 37 & -69 & -15 & 8.25 & 278 \\
\hline \multirow[t]{3}{*}{ S7 } & 'FFA' & 31 & -58 & -9 & 5.59 & 464 \\
\hline & 'OFA' & 24 & -73 & -10 & 5.59 & 171 \\
\hline & vLOC & 34 & -63 & -14 & 8.35 & 61 \\
\hline \multirow[t]{3}{*}{ S8 } & 'FFA' & 39 & -49 & -20 & 10 & 654 \\
\hline & 'OFA' & 35 & -67 & -18 & 10 & 64 \\
\hline & vLOC & 43 & -68 & -9 & 8.25 & 233 \\
\hline \multirow[t]{3}{*}{ S9 } & 'FFA' & 34 & -41 & -15 & 5.59 & 1795 \\
\hline & 'OFA' & 28 & -79 & -7 & 5.59 & 153 \\
\hline & vLOC & 41 & -71 & -6 & 6 & 567 \\
\hline \multirow[t]{3}{*}{ S10 } & 'FFA' & 39 & -47 & -18 & 9.6 & 91 \\
\hline & 'OFA' & 38 & -72 & -11 & 9.6 & 43 \\
\hline & vLOC & 38 & -41 & -18 & 3.6 & $263^{*}$ \\
\hline \multirow[t]{3}{*}{ S11 } & 'FFA' & 39 & -50 & -20 & 5.59 & 809 \\
\hline & 'OFA' & 38 & -71 & -16 & 5.59 & 916 \\
\hline & vLOC & 48 & -58 & -12 & 8.25 & 255 \\
\hline $\mathrm{S} 1-\mathrm{S} 10$ & 'FFA' & $36 \pm 4$ & $-48 \pm 6$ & $-15 \pm 4$ & - & $717 \pm 491$ \\
\hline $\mathrm{S} 1-\mathrm{S} 10$ & 'OFA' & $34 \pm 5$ & $-71 \pm 6$ & $-14 \pm 4$ & - & $756 \pm 833$ \\
\hline $\mathrm{S} 2-\mathrm{S} 10$ & vLOC & $41 \pm 5$ & $-65 \pm 9$ & $-11 \pm 4$ & - & $385 \pm 228$ \\
\hline
\end{tabular}

Note that the use of different statistical thresholds was done only to define our regions of interest in the different subjects, not to test our hypotheses. For these localizers, the same definition of statistical threshold for all subjects and areas was not the best procedure because of the variability in the differential fMRI response between subjects: the clear separation of the 3 regions of interest requested a more conservative threshold for a subset of subjects. Here, we report all information about the thresholds and size of regions for all individual subjects so that one can compare the patient PS with the controls. It is clear that at the same threshold, PS's 'FFA' is in the normal range of activation (as described previously, see Rossion et al., 2003; Sorger et al., 2007). For the majority of control participants, the statistical thresholds were the same as for the patient PS. Note also that if we use different thresholds within subject, the differential size of the ROI clusters have little if any effect on the adaptation effects observed for PS and our control subjects.

Remarks: ${ }^{*} q$ (False Discovery Rate $<0.05$, otherwise: clusters defined at $p<0.002$ (Bonferroni corrected for multiple comparisons). significant difference in reaction times (RTs) across conditions (same butterflies: $467 \mathrm{~ms}$; different butterflies: $471 \mathrm{~ms}$; same faces: $481 \mathrm{~ms}$; different faces: $476 \mathrm{~ms}$ ) or between control subjects and PS $(t=0.269$, $p=0.407$; modified $t$-test; Crawford and Garthwaite, 2002).

The 'FFA' and vLOC areas were tested for fMRI-adaptation to identity using the contrast (different vs. same) for each category. Below, we always report the results for the group (random) analysis ( $p$-value), as well as the highest individual $p$-value $\left(p_{\mathrm{s}}<\right)$ in the group of normal participants. Indeed, in line with our previous behavioral and neuroimaging work on the single case PS (Caldara et al., 2005; Rossion et al., 2003; Schiltz et al., 2006) we define the patient's results as abnormal when they present a different profile than every single control tested in the study.

For each control subject the neural activity was significantly larger when viewing pictures of faces than butterflies (all individual $p$-values: $\left.p_{\mathrm{s}}<0.000042\right)$ in the right 'FFA'. More interestingly, the response was significantly larger during a block for different faces than identical faces (random effect analysis: $p<0.0009$; individual $p$-values: $p_{\mathrm{s}}<0.000004$; Faces adaptation index $=0.177 \pm 0.072$ ) and when viewing different butterflies than identical butterflies (random effect analysis: $p<0.00002$; $p_{\mathrm{s}}<0.000008$; Objects Index $=0.253 \pm 0.054$ ) (Fig. 3). There was no interaction between repetition and category (random effect analysis: $p<0.37 ; p_{\mathrm{s}}$ ranging from 0.1 to 0.93 ). For PS, there was a larger response to faces than butterflies $(p<0.0082)$, but the difference between different and same faces was not significant (Index $=-0.060 ; p=0.507$ ), replicating previous observations (Schiltz et al., 2006). However, there was a significantly larger response for different pictures of butterflies than same pictures (Objects Index $=0.287$, contrast $p<0.035$ ) in PS's 'FFA'. When comparing PS's indices directly to controls, they were significantly different in the 'FFA' for Faces $(t=3.035, p<0.014$; modified $t$-test; Crawford and Garthwaite, 2002), but not for objects $(t=0.583$, $p=0.293$ ). As a result, she was the only participant presenting a significant interaction between the factors category and repetition $(p<0.049)$ (Fig. 3).

In the right 'OFA', located in a region structurally damaged in PS's brain (see Fig. 2; Rossion et al., 2003), all control subjects also showed a strong release from adaptation for both faces (random effect analysis: $p<0.005 ; p_{\mathrm{s}}<0.05$; Index $=0.142 \pm 0.05$ ) and butterflies (random effect analysis: $p<0.001 ; p_{\mathrm{s}} 0.015$ Index $=0.160 \pm$ 0.03 ) without any interaction (random effect analysis: $p>0.9 ; p_{\mathrm{s}}$ ranging from 0.26 to 0.94 ), i.e. the same response pattern as in the 'FFA'.

In the right vLOC of control subjects (Fig. 4), we found release from adaptation both to faces (random effect analysis: $p<0.002$; $p_{\mathrm{s}}<0.000004$; Faces Index $=0.194 \pm 0.06$ ) and butterflies (random effect analysis: $p<0.0006 ; p_{\mathrm{s}}<0.000008$; Objects Index $=0.187 \pm$ 0.03 ) without interaction (random effect analysis $p>0.65 ; p_{\mathrm{s}}: 0.12$ to 0.83 ). For PS, there was also a significant difference for butterflies (Objects Index $=0.161$, contrast $p<0.0000001$ ). Most importantly, in contrast to the absence of effect in the 'FFA', there was a significant release from adaptation for faces (Faces Index $=0.127$, contrast $p<0.0003$ ) in PS's vLOC (Fig. 4). When comparing PS's indices directly to controls, there was no significant difference in the vLOC for the Faces Index $(t=1.034, p=0.174)$ and for the Objects Index $(t=0.688, p=0.261)$. There was no interaction between repetition and category $(p=0.16)$ either.

To complement these observations, we ran a conjunction analysis using the contrasts (butterflies: different vs. same) and (faces: different vs. same) in the whole of the patient PS, without a 

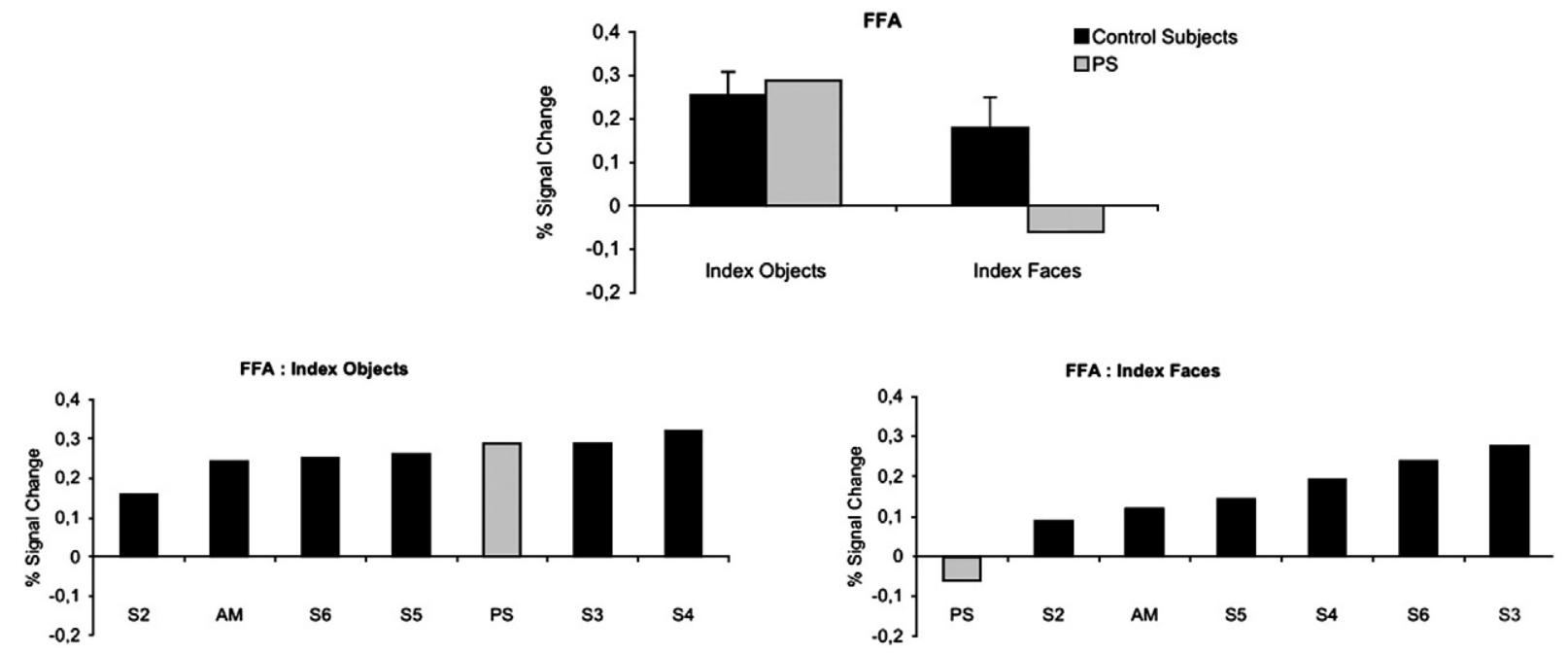

Fig. 3. Comparison between PS and the control subjects in the fMRI-adaptation block experiment 1 ('FFA'). Above: An adaptation index [(different-same)/ (different + same)] was computed for each category in PS's and each subject's 'FFA' using the beta weights of the GLM analysis. The Faces Index was significant for all subjects but PS, replicating previous observations (Schiltz et al., 2006). The adaptation index for objects was significant for PS, and of identical magnitude to the controls' index in the 'FFA'. Below: individual subject's indexes, showing that the deficit of release from adaptation in the 'FFA' of PS was found only for faces, not for objects.

priori localization. Strikingly, the coordinates of the only region significantly activated in the whole brain of the patient was in the vLOC $[43,-62,-17, q([$ False Discovery Rate $)<0.05,11$ voxels $]$ (Fig. 5). When we did the same whole brain conjunction with the control group, we found 4 areas at $p$ (bonf) $<0.001$ : (1) $35-42-17$, 801 voxels ['FFA' (see Table 1); face selective region: (Faces - Butterflies contrast) $p<0.0001]$; (2) $36-73-13,105$ voxels ['OFA' (see Table 1); face selective region: $p<0.0003$ ]; (3) $37-61$ $-15,448$ voxels [vLOC (see Table 1), not a face selective region $p<0.2$ ]; (4) $-36-44-17,523$ voxels [left 'FFA'; face selective region: $p<0.0001]$.
Finally, running the conjunction analysis separately for faces and objects, we observed for the patient PS an effect in the vLOC only for faces $[44,-62,-16, q(\mathrm{FDR})<0.05,122$ voxels], whereas several areas light up in the different vs. same contrast for objects: the vLOC $[42,-64,-15, q([\mathrm{FDR})<0.05,692$ voxels], an area in the parahippocampal gyrus responding highly to objects ['PPA'; 31 , $-32,-20, q([\mathrm{FDR})<0.05,103$ voxels $]$, a region of the precuneus $[15,-81,-40, q(\mathrm{FDR})<0.05,69$ voxels $]$ and the 'FFA' at a lower threshold [32-53-17, $p$ (uncorrected) $<0.04,107$ voxels].

In summary, these data show that the absence of release from adaptation in the 'FFA' of the brain damaged patient is restricted to
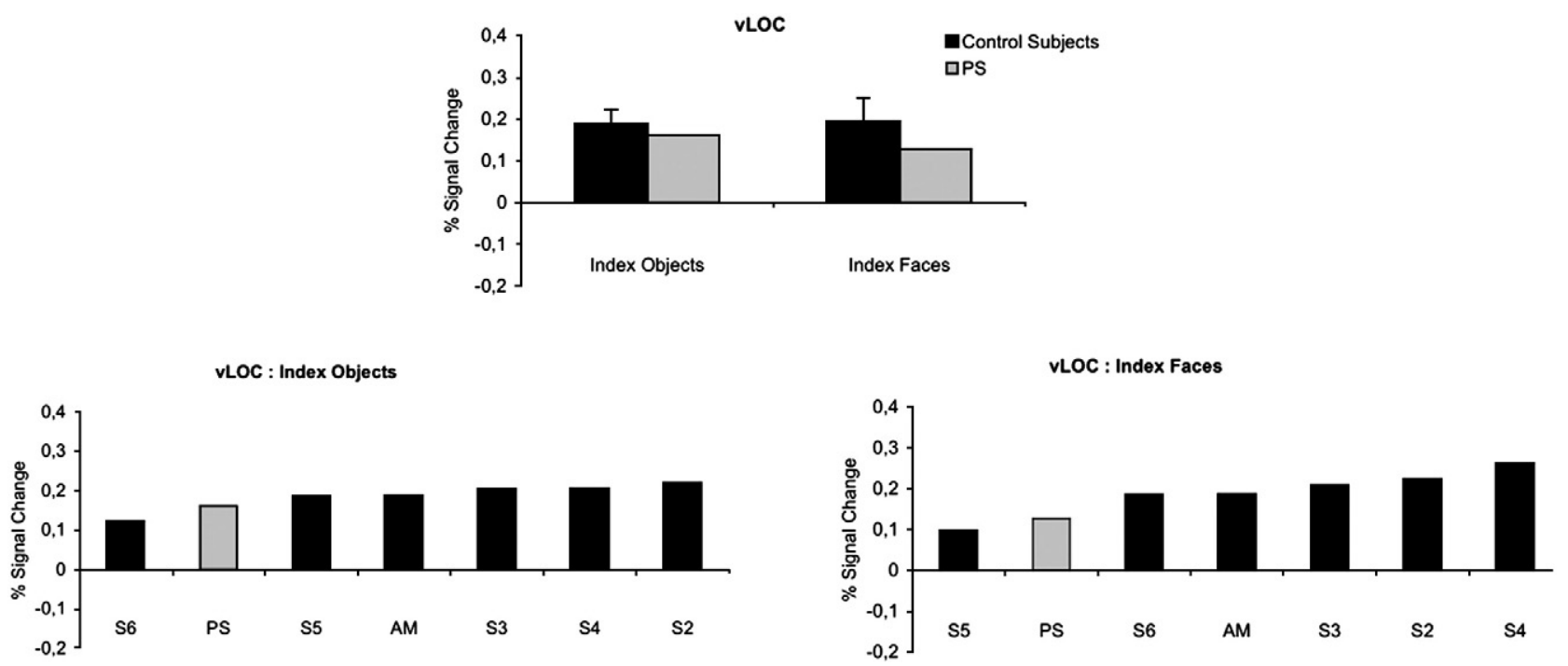

Fig. 4. Comparison between PS and the control subjects in the fMRI-adaptation block experiment 1 (vLOC). Above: An adaptation index [(different-same)/ (different + same)] was computed for each category in PS's and each subject's vLOC using the beta weights of the GLM analysis. The adaptation index was significant and of identical magnitude for all subjects and PS. Below: individual subject's indexes, showing that PS had normal adaptation indexes for both faces and objects in this experiment. 


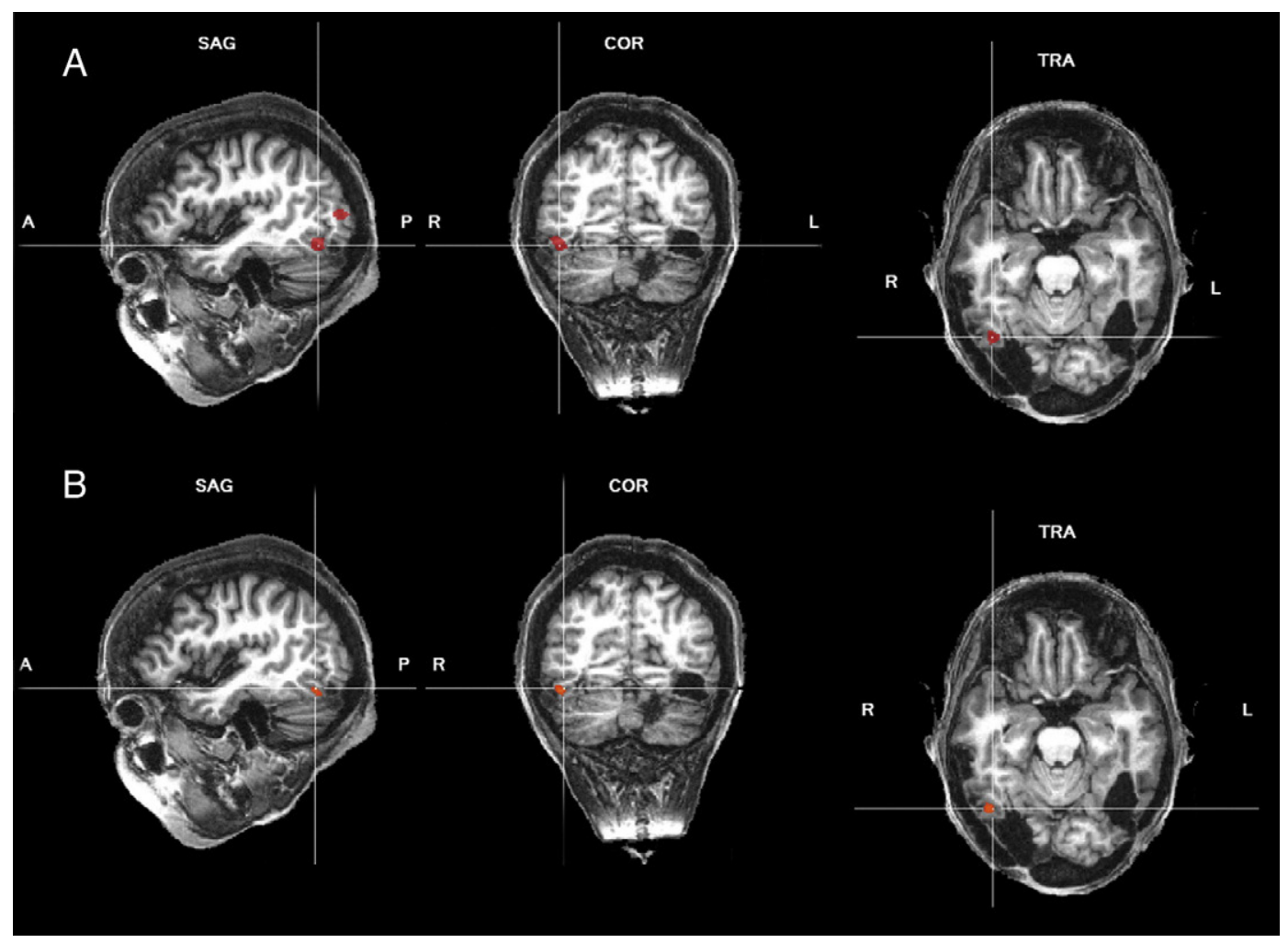

Fig. 5. Single subject analysis of patient PS in the fMRI-adaptation block experiment 1 . (A) Localization of the LOC: $t>6, p$ (Bonf) $<0.000$, vLOC: $43,-64,-12$ (632 voxels) and dLOC: $39,-77,3$ (485 voxels). (B) Results of the conjunction analysis using the contrasts (butterflies: different vs. same) and (faces: different vs. same). The coordinates of the only region significantly activated $[t>3.66, p<0.00025$ (uncorr.), 176 voxels (illustrated) and $q$ (False Discovery Rate) $<0.05$, 11 voxels] was in the vLOC (center: $43,-62,-17$ ).

face stimuli: there were large effects for non-face objects, as in the normal brain. Moreover, discrimination of individual faces in the patient's brain takes place only in an area that does not respond preferentially to faces: the vLOC. Normal participants also show release from adaptation in this area, suggesting that the patient's pattern of response is not due to cortical reorganization of function. However, normal participants also showed large release from adaptation effects in the 'FFA' and 'OFA' of the right hemisphere, functionally and structurally damaged in the patient's brain respectively.

\section{Event-related fMRI of faces and objects}

All participants performed the behavioral task of indicating across-category trials at ceiling (control means: $94 \pm 3.5 \%$ correct detection, no false alarm), PS (96\% correct detection, no false alarm). They were all quite fast and PS showed comparable response latencies to control subjects [controls: $599 \pm 147 \mathrm{~ms}$, PS: $576 \mathrm{~ms} ; t=0.703, p=0.266$ ).

Again, PS's and subjects' 'FFA' and vLOC were tested for fMRI-adaptation to identity using the contrast (different vs. same) for each category and an adaptation index was computed using the beta weights of the general linear model (GLM) analysis (Materials and methods). For each control subject, the neural activity was significantly larger when viewing pictures of faces than butterflies (individual $p$-values ranging from 0.000001 to 0.05 ) in the right 'FFA'. As in the block experiment 1 , the response was significantly larger for different faces than identical faces for normal participants (random effect analysis: $p<0.0285$; individual $p$-values: $p_{\mathrm{s}}<0.015$; Faces Index $=0.235 \pm 0.16$ ) and when viewing different butterflies than identical butterflies [random effect analysis: $p<0.010$; $p_{\mathrm{s}}<0.001$ except for S11 $(p=0.1)$; Objects Index $\left.=0.228 \pm 0.12\right]$ (Fig. 6). There was no interaction between repetition and category [random effect analysis: $p<0.23 ; p_{\mathrm{s}}$ ranging from 0.06 to 0.89 except for S11 $(p<0.04)$ who had a small effect for pictures of butterflies]. For PS, there was a larger response to faces than butterflies $(p<0.001)$, but the difference between different and same faces was not significant (Faces Index $=0.070 ; p=0.214$ ), replicating our block design experiment. There was also a significantly larger response for different pictures of butterflies than same pictures (Objects Index $=0.330$, contrast $p<0.042$ ) in PS's 'FFA'.

PS had the lowest adaptation index for faces of all subjects (i.e. 0.07 for PS vs. 0.235 for controls on average) even though it was not significantly different than the controls due to the large inter-subject variance in the 'FFA' for faces [ $t=0.984, p<0.199]$ (Fig. 6). Her adaptation index for butterflies was undistinguishable from the index of the controls $(t=0.688, p=0.270)$. Notably, she was the only participant presenting an adaptation index significantly larger for butterflies than faces [significant interaction between the factors category and repetition $(p<0.042)$, all other $p_{\mathrm{s}}>0.1$ ] (Fig. 6).

In the right vLOC of control subjects (Fig. 7), we found release from adaptation both to faces [random effect analysis: $p<$ $0.046 ; p_{\mathrm{s}}<0.003$ except for S1 $(p<0.36)$; Faces Index $=0.133 \pm$ 0.11 ] and butterflies [random effect analysis: $p<0.0147$; 


\section{A}

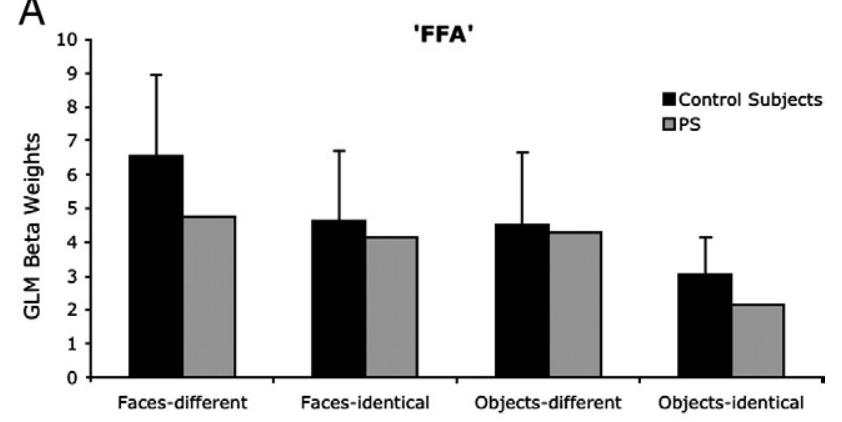

B

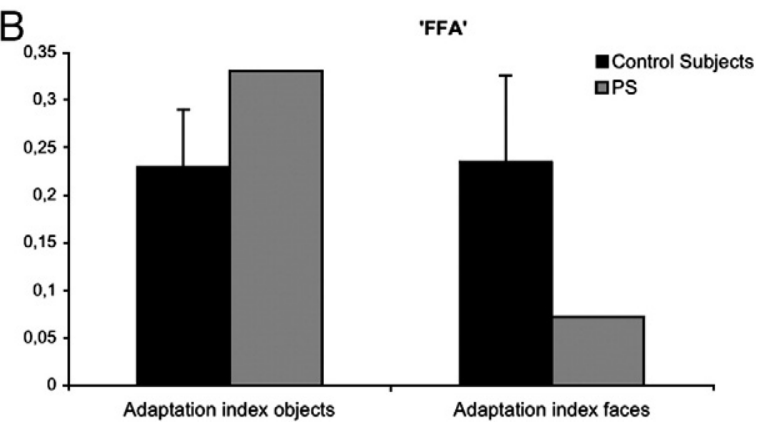

Fig. 6. (A) PS and normal control data for the 'FFA' (beta weights of the general linear model analysis) in the fMRI-adaptation experiment 2. PS was the only participant who did not show a significant release from adaptation to face identity while showing a significant effect for pictures of objects. (B) Adaptation indices for PS and normal controls in experiment 2 ('FFA').

$p_{\mathrm{S}}<0.031$ except for S1 $(p<0.22)$; Objects Index $\left.=0.112 \pm 0.05\right]$ without interaction (random effect analysis $p>0.456 ; p_{\mathrm{s}}: 0.19$ to 0.99). For PS, there was also a significant difference for butterflies (Objects Index $=0.140$, contrast $p<0.000001$ ). Most importantly, in contrast to the absence of effect in the 'FFA', there was a significant release from adaptation for faces (Faces Index $=0.063$, contrast $p<0.046$ ) in PS's vLOC (Fig. 7). When comparing PS's indices directly to controls, there was not significant difference in the vLOC for the Faces Index $[t=0.537, p=0.314)$, and for the Objects Index $(t=0.501$, $p=0.325$ ).

\section{Event-related fMRI during individual face discrimination}

Despite her prosopagnosia, PS succeeds in individual face discrimination above chance level, especially when the viewpoint between the face stimuli remains constant and she is given prolonged time to answer (Rossion et al., 2003; Schiltz et al., 2006). To test further whether the right vLOC could subtend the patient's residual individual face discrimination abilities, we tested PS and normal participants in an event-related paradigm during an active individual face discrimination task (Fig. 8A). Normal participants performed the discrimination task at ceiling during their three runs (mean $=99.1 \pm 0.74 \%$ ) whereas PS's accuracy was at $86.2 \%(12.2 \%$ of different faces considered as identical, and $15.5 \%$ of identical considered as different). PS (1379 ms across conditions) was also much slower $(t=6.169, p<0.000$, modified $t$-test; Crawford and Garthwaite, 2002) than the control subjects (659 $\mathrm{ms} \pm 113 \mathrm{~ms}$ ).
In this experiment (Figs. 8-10), there were strong releases from adaptation in both the 'FFA' (random effect analysis: $p<0.001$; individual $p_{\mathrm{s}}<0.048$; Faces Index $=0.083 \pm 0.049$ ) and the vLOC (random effect analysis: $p<0.012 ; p_{\mathrm{s}}<0.016$; Faces Index $=0.094 \pm 0.049$ ) of the normal participants. In contrast, PS did not show release from adaptation to individual faces in the 'FFA' (Index $=-0.025 ; p=0.46$ ) but a significant effect in the vLOC (Index $=0.098 ; p<0.00368$ ) only.

In the right 'OFA', all but one (S10) control subjects also showed a release from adaptation for faces (random effect analysis: $p<0.0047$ (or $p<0.03$ including the subject without significant release), individual $p_{\mathrm{s}}<0.043$; Index $=0.100 \pm 0.07$,) i.e. the same response pattern as in the 'FFA'.

When comparing PS's indices directly to those of the controls, there was a significant difference in the 'FFA' $(t=-2.041, p<$ 0.048; modified $t$-test; Crawford and Garthwaite, 2002), but not in the vLOC $(t=0.057, p=0.478)$, indicating that the magnitude of the effect was as large for PS and normal controls in this last area.

In the area where the different faces response is larger than the same faces response [i.e. corresponding to the vLOC area $(43,-63$, -17)] of the patient PS, we tested for any difference between faces and objects in the localizer. There was a significant difference, the data showing in fact a larger response to pictures of objects than faces $(p<0.015)$. Hence, PS is indeed using primarily a region that does not respond preferentially to faces to discriminate individual face exemplars. For normal controls, when we considered the regions showing the largest different $>$ same faces response in a whole brain random analysis, we found two areas at $p$ (uncorrected) $<0.01$ : (1) $37-35-16,108$ voxels and (2) $-30-45$
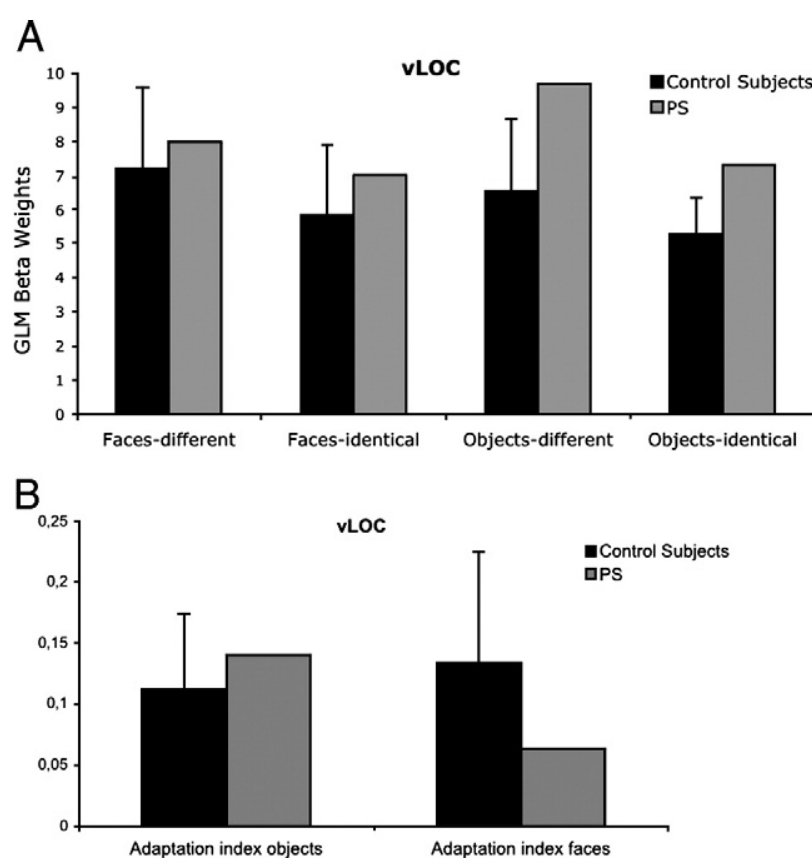

Fig. 7. (A) PS and normal control data for the vLOC (beta weights of the general linear model analysis) in the fMRI-adaptation experiment 2. All participants, including PS, showed a significant release from adaptation both to face and object identity. (B) Adaptation indices for PS and normal controls in experiment 2 (vLOC). 
A

a
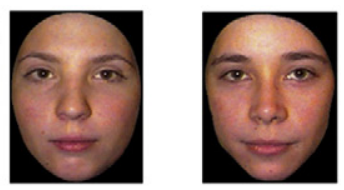

b
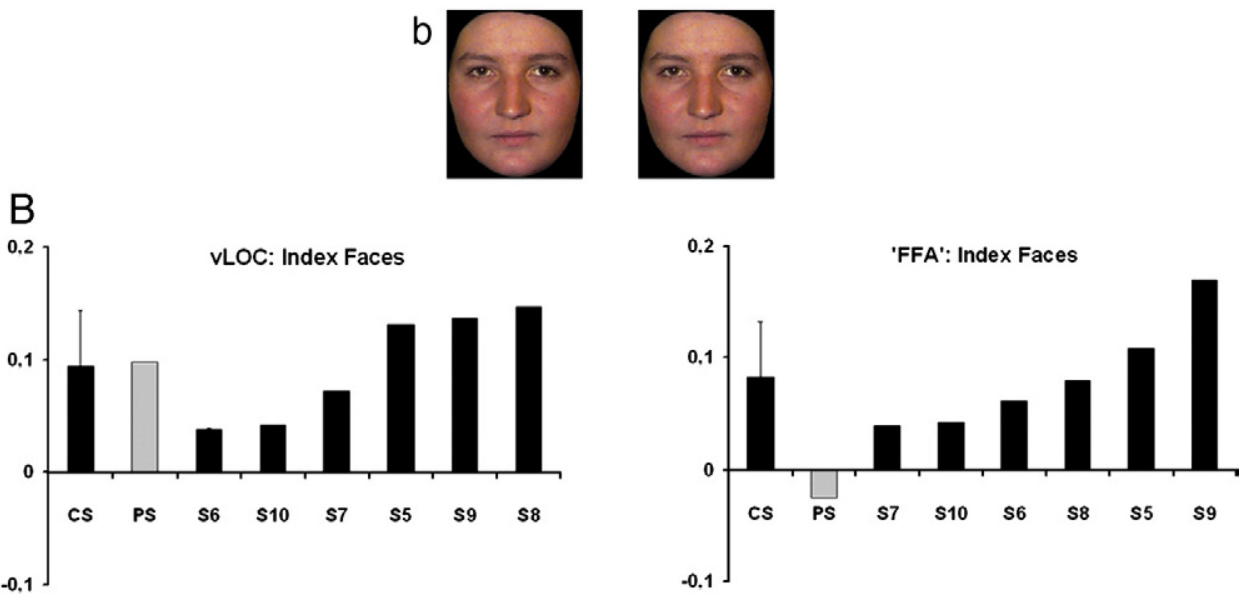

Fig. 8. Comparison between PS and the control subjects in the event-related fMRI-face discrimination experiment 3. (A) Two conditions were presented to PS and control subjects: second face different than the first (a) and second face identical to the first (b). All the faces were shown on frontal view presented in color and sustained a size of roughly $4^{\circ}$ of visual angle. The faces were cropped. (B) Comparison between PS and the control subjects (CS): a Faces Index [(differentsame)/(different+same)] was computed for PS's and each subject's vLOC and 'FFA' using the beta weights of the GLM analysis. The Faces Index in the 'FFA' was significant for all subjects but PS, contrary to her adaptation index in the vLOC, which is significant and of identical magnitude to the control's index.

-12 334 voxels, which correspond to two face selective regions in all our subjects (highest individual $p$-value $p_{\mathrm{s}}<0.0001$ and 0.0007 respectively).

To sum up, the results of this third event-related fMRI experiment confirms that the active discrimination of individual faces in the patient's brain take place in the vLOC, despite the absence of any such effect in the area responding preferentially to faces, the 'FFA'.

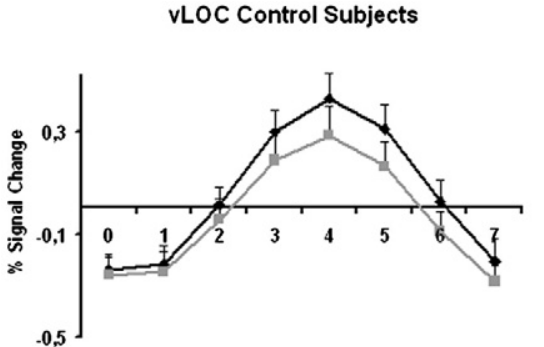

Time

'FFA' Control Subjects

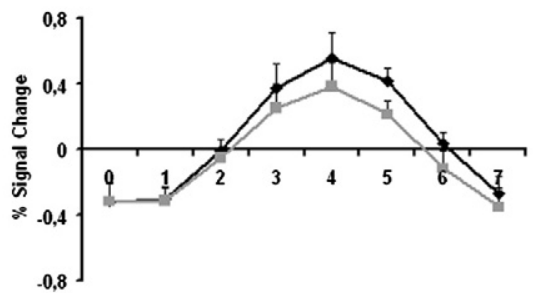

Time

\section{Discussion}

Our three fMRI-adaptation experiments carried out with normal participants and the brain-damaged prosopagnosic patient PS show two novel observations.

1. In the same high-level visual area, i.e. the 'FFA', the processes allowing for the discrimination of individual members of a

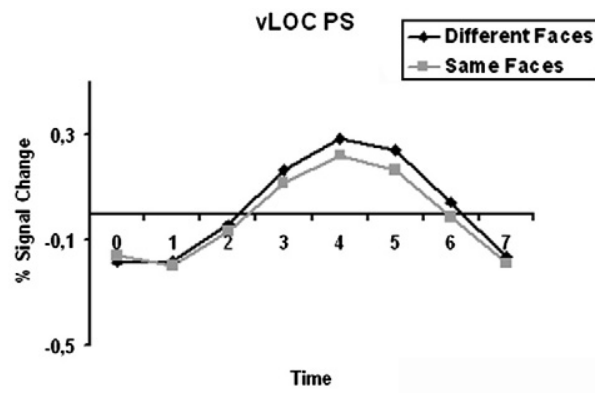

'FFA' PS

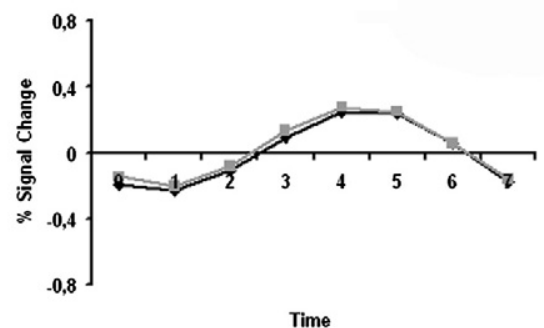

Fig. 9. PS's and control subjects' time-courses in the right-hemispheric vLOC and 'FFA' in the event-related fMRI-face discrimination experiment 3. PS did not show any evidence of a release from adaptation in the 'FFA', but normal effects in the vLOC. 
$\leftarrow$ Different Faces

- Same Faces

VLOC

$\mathbf{5 5}$

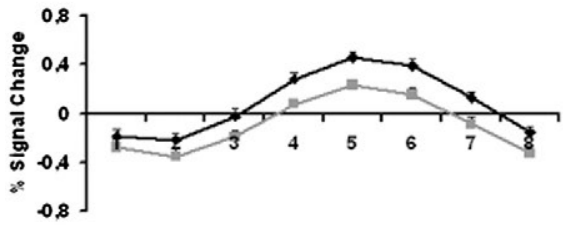

Time

56

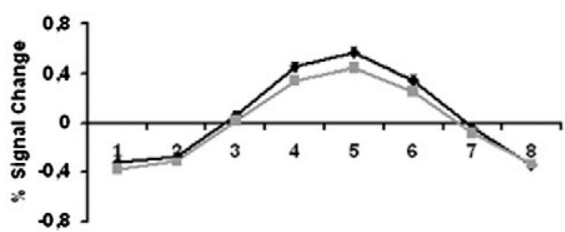

Time

s7

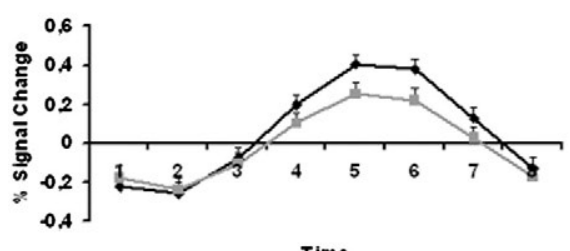

S8

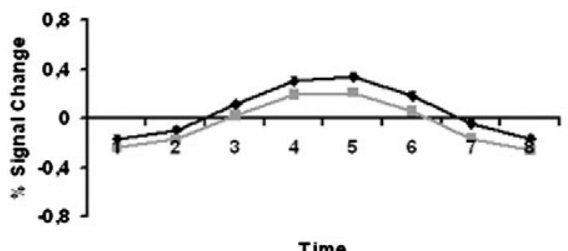

$\mathbf{5 9}$

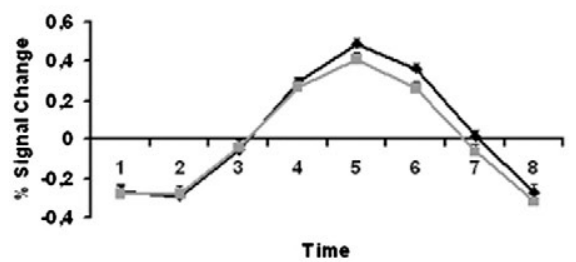

$\mathbf{s 1 0}$

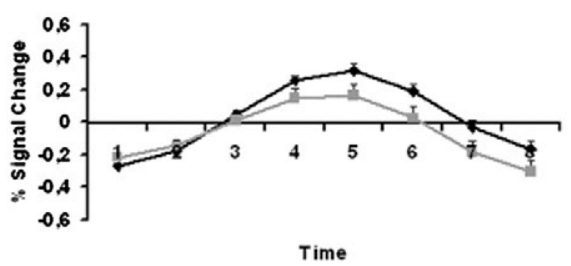

'FFA'

S5

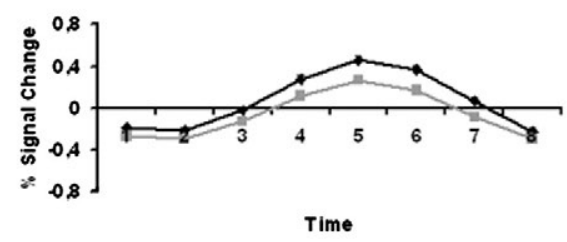

S6

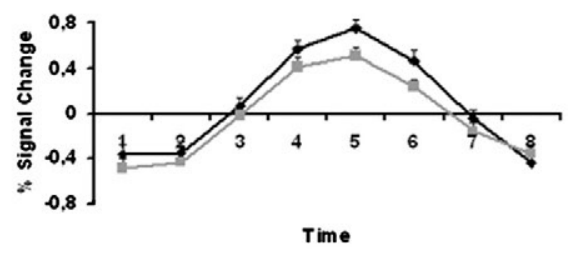

s7

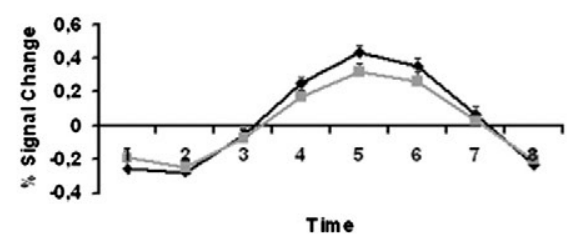

$\mathbf{5 8}$

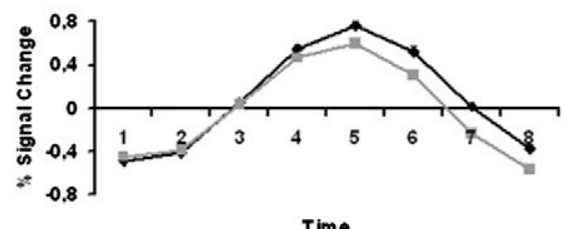

$\mathbf{S 9}$

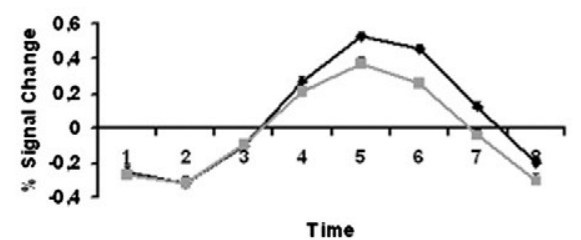

$\mathbf{5 1 0}$

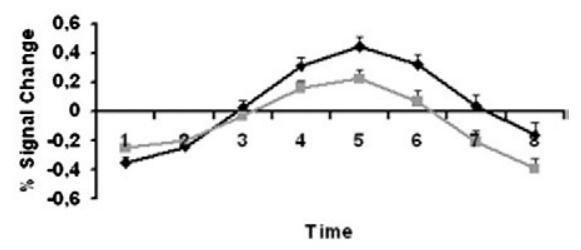

Fig. 10. Individual time-courses in the right-hemispheric vLOC and 'FFA' in the event-related fMRI-face discrimination experiment 3. 
visual category can be preserved for non-face objects but is impaired for faces. This suggests that faces and non-face objects responses in this area are functionally independent.

2. High-level visual areas that do not respond preferentially to faces, such as the vLOC, subtend complementary visual processes to discriminate individual faces. The data strongly suggest that these processes are both independent from processes taking place in areas responding maximally to faces ('FFA' and 'OFA') and insufficient to carry normal face perception.

\section{Selective preservation of individual object perception in the 'FFA'}

In rare cases of prosopagnosia, object perception is intact and impairments are restricted to faces (e.g. De Renzi and di Pellegrino, 1998; Henke et al., 1998; Sergent and Signoret, 1992) even when RTs are considered during fine visual discrimination within the same object category (Schiltz et al., 2006). What is the neural basis of this preserved object perception ability in prosopagnosia? We showed previously that the acquired prosopagnosic patient PS presents a right hemisphere lesion encompassing the 'OFA' (Rossion et al., 2003) but leaving the entire LOC intact (Sorger et al., 2007). The data collected here further indicate that neurons in the patient's right vLOC carry out discrimination of individual exemplars of objects, as in normal subjects. More interestingly, while we replicated the absence of such identity adaptation effects for faces (Schiltz et al., 2006) in three experiments, we observed for the first time fMRI-adaptation effects for objects in the 'FFA' of PS. Thus, within-category object discrimination can takes place in both the vLOC and the 'FFA' in the patient's visual cortex, in line with her normal behavioral performance at such tasks (Rossion et al., 2003; Schiltz et al., 2006).

Why do we observe a preserved release from adaptation to individual object exemplars in the patient's 'FFA' while there is no such effect for faces? Obviously, this cannot be due to a lower sensitivity of this area to faces, because its response is higher to faces for both normal controls and the patient PS. Moreover, this dissociation observed in PS's 'FFA' is unlikely to be due to attentional confounds (Eger et al., 2004a; Kanwisher and Wojciulik, 2000; Schiltz et al., 2006). First, one would have to posit that attention was increased only when different objects were shown during a block in experiment 1 , not during the presentation of different faces, and this only for the patient. Second, the results were also found in an event-related paradigm (experiment 2), when the order of conditions was unpredictable, limiting the possibility of attentional confounds. Finally, we used an identical orthogonal task for both categories, for which the patient performs at the same level in all conditions and as well as the controls.

One may argue that the individual pictures of objects used (butterflies) were more dissimilar than the individual faces (Fig. 2, see Materials and methods), a factor that could potentially explain why significant release from identity adaptation is found in PS's 'FFA' for objects but not for faces. As we indicated earlier, testing our hypothesis required to maximize our chances to observe significant releases from adaptation to objects in the 'FFA' of every single participant of the study, hence using individual exemplars of an object category differing substantially in shape, color and texture. However, as far as shape and texture are concerned, individual exemplars of the 2 categories were roughly equally distinct, or even more similar for butterflies (see Materials and methods). Moreover, in the present study we also used exemplars of faces that differed substantially in shape (internal and external features including hairstyle, etc.) and surface properties, including color. This point is worth to note because it strengthens our previous observations of a lack of release from face identity adaptation with the patient PS using pictures of faces without external features (Schiltz et al., 2006). In addition to this point, identity adaptation effects in the present study were equally large for individual exemplars of objects and faces in the vLOC of the control participants (Fig. 4). Thus, it is unlikely that the absence of significant release from identity adaptation restricted to faces in PS's 'FFA' may be due to a simple factor such a higher physical similarity of face exemplars over object exemplars.

More generally, even though we used the exact same images, the effects of adaptation that we observed in these areas for objects and faces are unlikely to be due to simple image-based cues. First, these cues were minimized by jittering the stimuli in position, a factor that decreases substantially pixel-similarity indexes (GrillSpector and Malach, 2001; Rossion and Jacques, in press) and yet leads to substantial release from adaptation as in previous studies (e.g. Fang et al., 2007; Schiltz et al., 2006). Second, in the whole brain analysis of the patient PS, we found significant release from adaptation in high-level visual areas only: the vLOC for faces, the 'FFA', vLOC and 'PPA' for objects. Finally, and more generally, it is likely that identity adaptation effects found for faces and objects in the 'FFA' in the present and previous studies are not only driven by high-level visual cues, but also by low-level cues which are naturally used to discriminate individual exemplars (e.g. eye color, hairstyle, contour, etc.). This information is part of what defines an individual object or face representation for our visual system (e.g. see Lee and Perrett, 1997 for the role of color in individual face perception). Neuroimaging experiments performed in normal viewers will have to clarify the nature of the face cues that leads to identity adaptation effects in the 'FFA' (and other 'face areas'), something that is currently unknown. While a substantial part of these effects may be driven by high-level cues (e.g. symmetry; Chen et al., 2007; holistic integration of facial features; Schiltz and Rossion, 2006), low-level information on local cues (e.g. eye color, mouth shape, etc.) certainly contributes to these effects. It is particularly interesting that a prosopagnosic patient such as PS, despite being able to use such "low-level" cues to discriminate individual faces at least to some extent (see Caldara et al., 2005), does not recruit her face-preferential activation in the fusiform gyrus ('FFA') for this process.

The dissociation between the adaptation effects for objects and faces in the 'FFA' is particularly interesting because the same highlevel visual area, defined on the basis of a functional criterion, shows abnormal discriminative responses to items of one category - faces - while presenting normal responses to another category (here, pictures of butterflies). Thus, non-face individual discrimination in the 'FFA' is preserved for PS, and these lower responses may well play a role in her preserved object discrimination abilities, in line with earlier proposals (Avidan et al., 2002; Haxby et al., 2001).

There is recent evidence suggesting that these lower responses to objects in the 'FFA' do not originate from the same populations than the responses to faces. Using high-resolution fMRI, GrillSpector (Grill-Spector et al., 2006b; Grill-Spector et al., 2007) found that the 'FFA' is not an unitary region, but rather contains clusters of highly selective neurons responding preferentially to 
faces intermixed with fewer clusters that are non-selective for any object category (Grill-Spector et al., 2006b; Grill-Spector et al., 2007). ${ }^{1}$ This concur with earlier single-cell recording data in the monkey brain, showing that the areas of the infero-temporal (IT) cortex, such as the lower bank of the superior temporal sulcus (STS), contains between $10 \%$ and $20 \%$ of face-selective neurons (Baylis et al., 1987) intermixed with neurons coding for non-face moderately complex features (Logothetis and Sheinberg, 1996; Tanaka et al., 1991). More recently, Tsao (Tsao et al., 2006) recorded from localized fMRI 'face areas' in the monkey brain and found that almost all cells (about 97\%) within these areas responded selectively to faces. However, the authors made only a few recordings, most likely from the same highly face-selective clusters of cells in these areas. Hence, these observations are not in disagreement with the finding that the area as whole contains clusters of cells that are non-selective for faces (Grill-Spector et al., 2006b; Grill-Spector et al., 2007) and which may explain the release from adaptation to objects in the 'FFA' observed here and in previous studies.

Given these observations, one plausible interpretation of our findings is that the clusters of face-cells in the anatomically preserved 'FFA' of PS do not show enough specificity in their response to distinct facial identities (Schiltz et al., 2006). This lack of sensitivity to facial identity in the 'FFA' may be due to a lack of inputs from the lesioned right 'OFA', a region where release from adaptation effects were observed here in normal subjects, as in previous studies (see Schiltz et al., 2006). However, non-face object clusters in the same area may still code for distinct objects, perhaps based on moderately complex features, leading to the release from adaptation to objects that we observed here. Future experiments combining high-resolution fMRI with object and face adaptation paradigms should be able to test this hypothesis.

\section{Residual perception of individual faces subserved by $v L O C$ neurons}

Despite her massive prosopagnosia, PS's performance in individual face discrimination tasks remains well above chance level, especially when there is no change in viewpoint between the faces to compare, and she is given unlimited time to answer (Rossion et al., 2003; Schiltz et al., 2006). Here, in the active face discrimination task during the ER adaptation experiment, she scored at $86 \%$ and was slowed down relative to controls, who performed at ceiling. Such residual abilities are commonly observed in prosopagnosic patients, who may obtain relatively good scores at the Benton face matching tests (Benton and Van Allen, 1968) with unlimited time presentation (Bukach et al., 2006; Davidoff and Landis, 1990; Delvenne et al., 2004; Levine and Calvanio, 1989; Sergent and Signoret, 1992). There is now strong

\footnotetext{
${ }^{1}$ Note that the original contribution of Grill-Spector and colleagues (Grill-Spector, K., Sayres, R., and Ress, D., (2006b). High-resolution imaging reveals highly selective nonface clusters in the fusiform face area. Nat Neurosci 9, 1177-1185.) reported clusters in the 'FFA' that were highly selective for non-face object categories, but these conclusions were dismissed and these clusters rather appear as non-category selective [see Baker et al. (2007) and Simmons et al. (2007)]. However, the conclusion that the 'FFA' is a heterogenous region in humans remains entirely valid [Grill-Spector, K., Sayres, R., and Ress, D. (2007). Corrigendum: Highresolution imaging reveals highly selective nonface clusters in the fusiform face area. Nat Neurosci 10, 133.].
}

evidence that these residual individual face discrimination abilities are not subtended by the 'FFA' of the patient, since this region does not show release from adaptation effects to identity, no matter the different procedures and stimuli used (Schiltz et al., 2006; the present experiments).

In contrast to the absence of adaptation effects in the 'FFA' for faces, the whole brain analysis in the first experiment, testing for adaptation effects to face identity, revealed a significant effect in the right $\mathrm{VLOC}$, next to the patient's posterior lesion. The second and third experiment confirmed that this area was sensitive to different facial identities. We believe that this is an interesting observation, for three reasons.

First, to our knowledge, release from adaptation to facial identity has not been described, or emphasized before in normal subjects in areas that do not respond preferentially to faces. Normal subjects appear to rely on several visual areas to discriminate individual faces, some responding preferentially to this category ('FFA', 'OFA'; the STS also, see Winston et al., 2004), while others do not (e.g. vLOC). Thus, responses in areas that do not process faces preferentially, such as the vLOC, may play a role in face categorization (Avidan et al., 2002; Haxby et al., 2001). This view is strengthened here by the observation that, in the patient's brain, the only remaining area subtending individual face discrimination was the vLOC. Since normal controls also show face adaptation effects in this area, the residual ability to discriminate individual faces in the patient's vLOC cannot be attributed to a functional reorganization, but rather to a residual, compensatory process. Similarly to our discussion of the origin of the effect for objects in the 'FFA', the face adaptation effect in the vLOC may originate from sub-populations of neurons tuned selectively to faces. However, to our knowledge, there is no reliable evidence for the presence of such face-selective population responses in the vLO. More generally, our conclusions that faces are processed by nonface selective mechanisms for the patient PS hold true for the level of organization corresponding to brain areas at current (low) fMRI resolution.

Second, individual face discrimination in vLOC may be independent of the processes carried out in the 'FFA' (or 'OFA'). PS's data strongly support this view because there was no evidence of individual face discrimination in the latter regions: the 'OFA' is structurally damaged and the 'FFA' does not show release from adaptation to face identity. These observations suggest that there are multiple processes, with a certain degree of independence, which allow the extraction of individual face representations in the normal brain. When the most efficient processes, calling on the 'FFA' and 'OFA', are unavailable, one may still rely on alternative processes in areas that do not respond mainly to faces (e.g. vLOC).

Third, the discriminative responses of facial identities observed in the VLOC of the patient and in the normal brain are insufficient to carry efficient face discrimination behavior. Whereas the role of the 'OFA', and most probably the 'FFA' is critical for efficient discrimination of individual faces and perception (Barton et al., 2002; Bouvier and Engel, 2006; Rossion et al., 2003; Schiltz et al., 2006) the vLOC appears to carry different and complementary functions that may or may not be necessary for face processing. To clarify whether this region is necessary, one would need to test patients with lesions selectively disrupting vLOC while leaving the two areas responding preferentially to faces intact. To our knowledge, such cases have not been reported, and are very unlikely to be found given the proximal location of these areas. Indeed, most cases of prosopagnosia following occipito-temporal 
right hemisphere lesions, usually following a posterior cerebral artery infarct (Goldsmith and Liu, 2001), present deficit at both face and object recognition (Barton et al., 2002; Bouvier and Engel, 2006; Clarke et al., 1997; Damasio et al., 1982; Farah, 1990; Gauthier et al., 1999; Rossion et al., 2003; Schiltz et al., 2006). Future investigations will have to clarify the nature of complementary processes allowing a certain level of individual face discrimination that can be performed by the vLOC, for both the patient and the control. One hypothesis is that the prosopagnosic patient's over reliance on non-diagnostic facial features to discriminate faces such as the mouth at the expense of the eyes (Caldara et al., 2005), or her feature-by-feature analysis due to an individual holistic face perception defect (Ramon and Rossion, 2007) may be subtended by non-face areas such as the vLOC.

\section{Conclusions}

Our results show that the right fusiform gyrus ('FFA') in the patient's brain can be impaired for discriminating individual items of its preferential category, faces, while being able to carry out interindividual object discrimination, in line with the behavior of the patient. Thus, the same brain area can be functional for one category and disrupted for another. Second, we observed a larger signal to different faces than same faces in the ventral part of the lateral occipital complex (vLOC), next to the lesioned area. These results indicate that faces are processed through a network of visual areas in the human brain, in line with a distributed view of face perception. However the subset of areas responding preferentially to faces ('FFA' and 'OFA') is critical for efficient individual face processing. Following damage to these areas, other areas that do not respond preferentially to faces such as the vLOC may still subtend residual individual face processes.

\section{Acknowledgments}

We are grateful to PS for her especially great patience during the experiments and to all our control subjects. LD was supported by a research grant (FSR) from the Université catholique de Louvain; BR is supported by the Belgian National Foundation for Scientific Research (FNRS).

\section{References}

Avidan, G., Hasson, U., Hendler, T., Zohary, E., Malach, R., 2002. Analysis of the neuronal selectivity underlying low fMRI signals. Curr. Biol. 12, 964-972.

Baker, C., Hutchison, I., Kanwisher, L., 2007. Does the fusiform face area contain subregions highly selective for nonfaces? Nat. Neurosci. 10, 3-4.

Bar, M., Tootell, R.B., Schacter, D.L., Greve, D.N., Fischl, B., Mendola, J.D., Rosen, B.R., Dale, A.M., 2001. Cortical mechanisms specific to explicit visual object recognition. Neuron 29, 529-535.

Barton, J.J., Press, D.Z., Keenan, J.P., O’Connor, M., 2002. Lesions of the fusiform face area impair perception of facial configuration in prosopagnosia. Neurology 58, 71-78.

Baylis, G.C., Rolls, E.T., Leonard, C.M., 1987. Functional subdivisions of the temporal lobe neocortex. J. Neurosci. 7, 330-342.

Benton, A.L., Van Allen, M.W., 1968. Impairment in facial recognition in patients with cerebral disease. Trans. Am. Neurol. Ass. 93, 38-42.
Benton, A.L., Van Allen, L.W., 1972. Prosopagnosia and facial discrimination. J. Neurol. 167-172.

Bodamer, J. (1947). Die-Prosop-agnosie. Arch Psychiatr Nervenkrankh 179, $6-54$.

Bouvier, S.E., Engel, S.A., 2006. Behavioral deficits and cortical damage loci in cerebral achromatopsia. Cereb. Cortex 16, 183-191.

Boynton, G.M., Engel, S.A., Glover, G.H., Heeger, D.J., 1996. Linear systems analysis of functional magnetic resonance imaging in human V1. J. Neurosci. 16, 4207-4221.

Brodtmann, A., Puce, A., Syngeniotis, A., Darby, D., Donnan, G., 2003. The functional magnetic resonance imaging hemodynamic response to faces remains stable until the ninth decade. NeuroImage 20, $520-528$.

Bukach, C.M., Bub, D.N., Gauthier, I., Tarr, M.J., 2006. Perceptual expertise effects are not all or none: spatially limited perceptual expertise for faces in a case of prosopagnosia. J. Cogn. Neurosci. 18, 48-63.

Caldara, R., Schyns, P., Mayer, E., Smith, M., Gosselin, L., Rossion, F., 2005. Does prosopagnosia take the eyes out of face representations? Evidence for a defect in representing diagnostic facial information following brain damage. J. Cogn. Neurosci. 17, 1652-1666.

Chen, C.C., Kao, K.L., Tyler, C.W., 2007. Face configuration processing in the human brain: the role of symmetry. Cereb. Cortex 17, 1423-1432.

Clarke, S., Lindemann, A., Maeder, P., Borruat, F.X., Assal, G., 1997. Face recognition and postero-inferior hemispheric lesions. Neuropsychologia $35,1555-1563$.

Crawford, J.R., Garthwaite, P.H., 2002. Investigation of the single case in neuropsychology: confidence limits on the abnormality of test scores and test score differences. Neuropsychologia 40, 1196-1208.

Damasio, A.R., Damasio, H., Van Hoesen, G.W., 1982. Prosopagnosia: anatomic basis and behavioral mechanisms. Neurology 32, 331-341.

Davidoff, J., Landis, T., 1990. Recognition of unfamiliar faces in prosopagnosia. Neuropsychologia 28, 1143-1161.

Delvenne, J.F., Seron, X., Coyette, F., Rossion, B., 2004. Evidence for perceptual deficits in associative visual (prosop)agnosia: a single-case study. Neuropsychologia 42, 597-612.

De Renzi, E., di Pellegrino, G., 1998. Prosopagnosia and alexia without object agnosia. Cortex 34, 403-415.

Eger, E., Henson, R.N., Driver, J., Dolan, R.J., 2004a. Bold repetition decreases in object-responsive ventral visual areas depend on spatial attention. J. Neurophysiol. 92, 1241-1247.

Eger, E., Schyns, P.G., Kleinschmidt, A., 2004b. Scale invariant adaptation in fusiform face-responsive regions. NeuroImage 22, 232-242.

Fang, F., Murray, S.O., He, S., 2007. Duration-dependent FMRI adaptation and distributed viewer-centered face representation in human visual cortex. Cereb. Cortex 17, 1402-1411.

Farah, M.J., 1990. Visual Agnosia: Disorders of Object Recognition and What They Tell us About Normal Vision. Cambridge MIT Press.

Gauthier, I., Behrmann, M., Tarr, M.J., 1999. Can face recognition really be dissociated from object recognition? J. Cogn. Neurosci. 11, 349-370.

Gauthier, I., Skudlarski, P., Gore, J.C., Anderson, A.W., 2000a. Expertise for cars and birds recruits brain areas involved in face recognition. Nat. Neurosci. 3, 191-197.

Gauthier, I., Tarr, M.J., Moylan, J., Skudlarski, P., Gore, J.C., Anderson, A.W., 2000b. The fusiform "face area" is part of a network that processes faces at the individual level. J. Cogn. Neurosci. 12, 495-504.

Gilaie-Dotan, S., Malach, R., 2007. Sub-exemplar shape tuning in human face-related areas. Cereb. Cortex 17, 325-338.

Goldsmith, Z.G., Liu, G.T., 2001. Facial recognition and prosopagnosia: past and present concepts. Neuro-ophthalmology 25, 177-192.

Grill-Spector, K., Malach, R., 2001. fMR-adaptation: a tool for studying the functional properties of human cortical neurons. Acta Psychol. (Amst.) 107, 293-321.

Grill-Spector, K., Malach, R., 2004. The human visual cortex. Annu. Rev. Neurosci. 27, 649-677.

Grill-Spector, K., Kushnir, T., Hendler, T., Edelman, S., Itzchak, Y., Malach, R., 1998. A sequence of object-processing stages revealed by fMRI in the human occipital lobe. Hum. Brain Mapp. 6, 316-328. 
Grill-Spector, K., Kushnir, T., Edelman, S., Avidan, G., Itzchak, Y., Malach, R., 1999. Differential processing of objects under various viewing conditions in the human lateral occipital complex. Neuron 24, 187-203.

Grill-Spector, K., Kushnir, T., Hendler, T., Malach, R., 2000. The dynamics of object-selective activation correlate with recognition performance in humans. Nat. Neurosci. 3, 837-843.

Grill-Spector, K., Kourtzi, Z., Kanwisher, N., 2001. The lateral occipital complex and its role in object recognition. Vision Res. 41, 1409-1422.

Grill-Spector, K., Knouf, N., Kanwisher, N., 2004. The fusiform face area subserves face perception, not generic within-category identification. Nat. Neurosci. 7, 555-562.

Grill-Spector, K., Henson, R., Martin, A., 2006a. Repetition and the brain: neural models of stimulus-specific effects. Trends Cogn. Sci. 10, 14-23.

Grill-Spector, K., Sayres, R., Ress, D., 2006b. High-resolution imaging reveals highly selective nonface clusters in the fusiform face area. Nat. Neurosci. 9, 1177-1185.

Grill-Spector, K., Sayres, R., Ress, D., 2007. Corrigendum: high-resolution imaging reveals highly selective nonface clusters in the fusiform face area. Nat. Neurosci. 10, 133.

Haxby, J.V., Gobbini, M.I., Furey, M.L., Ishai, A., Schouten, J.L., Pietrini, P., 2001. Distributed and overlapping representations of faces and objects in ventral temporal cortex. Science 293, 2425-2430.

Henke, K., Schweinberger, S.R., Grigo, A., Klos, T., Sommer, W., 1998. Specificity of face recognition: recognition of exemplars of non-face objects in prosopagnosia. Cortex 34, 289-296.

Henson, R.N., Rugg, M.D., 2003. Neural response suppression, haemodynamic repetition effects, and behavioural priming. Neuropsychologia 41, $263-270$.

James, T.W., Humphrey, G.K., Gati, J.S., Menon, R.S., Goodale, M.A., 2000. The effects of visual object priming on brain activation before and after recognition. Curr. Biol. 10, 1017-1024.

Kanwisher, N., Wojciulik, E., 2000. Visual attention: insights from brain imaging. Nat. Rev., Neurosci. 1, 91-100.

Kanwisher, N., McDermott, J., Chun, M.M., 1997. The fusiform face area: a module in human extrastriate cortex specialized for face perception. J. Neurosci. 17, 4302-4311.

Kleinschmidt, A., Cohen, L., 2006. The neural bases of prosopagnosia and pure alexia: recent insights from functional neuroimaging. Curr. Opin. Neurol. 19, 386-391.

Lee, K.J., Perrett, D.I., 1997. Presentation-time measures of the effects of manipulations in color space on discrimination of famous faces. Perception 26, 733-752.

Levine, D.N., Calvanio, R., 1989. Prosopagnosia: a defect in visual configural processing. Brain Cogn. 10, 149-170

Loffler, G., Yourganov, G., Wilkinson, F., Wilson, H.R., 2005. fMRI evdence for the neural representation of faces. Nat. Neurosci. 8, 1386-1390.

Logothetis, N.K., Sheinberg, D.L., 1996. Visual object recognition. Annu. Rev. Neurosci. 19, 577-621.

Malach, R., Reppas, J.B., Benson, R.R., Kwong, K.K., Jiang, H., Kennedy, W.A., Ledden, P.J., Brady, T.J., Rosen, B.R., Tootell, R.B., 1995. Object-related activity revealed by functional magnetic resonance imaging in human occipital cortex. Proc. Natl. Acad. Sci. U. S. A. 92, 8135-8139.

Oldfield, R.C., 1971. The assessment and analysis of handedness: the Edinburgh inventory. Neuropsychologia 9, 97-113.

Price, C.J., Friston, K.J., 1999. Scanning patients on tasks they can perform. Hum. Brain Mapp. 8, 102-108.
Quaglino, A., Borelli, G.B., Della Sala, S., Young, A.W., 2003. Quaglino's 1867 case of prosopagnosia. Cortex 39, 533-540.

Ramon, M., Rossion, B., 2007. What's lost in prosopagnosia? An investigation of familiar face processing in a single-case of pure prosopagnosia working in a kindergarten. J. Vis. Abstr. 7, 9, 122a doi:10.1167/7.9.122.

Rossion, B., Jacques, C., in press. Does physical interstimulus variance account for early electrophysiological face sensitive responses in the human brain? Ten lessons on the N170 NeuroImage.

Rossion, B., Caldara, R., Seghier, M., Schuller, A.M., Lazeyras, F., Mayer, E., 2003. A network of occipito-temporal face-sensitive areas besides the right middle fusiform gyrus is necessary for normal face processing. Brain 126, 2381-2395.

Rotshtein, P., Henson, R.N., Treves, A., Driver, J., Dolan, R.J., 2005 Morphing Marilyn into Maggie dissociates physical and identity face representations in the brain. Nat. Neurosci. 8, 107-113.

Sayres, R., Grill-Spector, K., 2006. Object-selective cortex exhibits performance-independent repetition suppression. J. Neurophysiol. 95, 995-1007.

Schiltz, C., Rossion, B., 2006. Faces are represented holistically in the human occipito-temporal cortex. NeuroImage 32, 1385-1394.

Schiltz, C., Sorger, B., Caldara, R., Ahmed, F., Mayer, E., Goebel, R., Rossion, B., 2006. Impaired face discrimination in acquired prosopagnosia is associated with abnormal response to individual faces in the right middle fusiform gyrus. Cereb. Cortex 16 , 574-586.

Sergent, J., Signoret, J.L., 1992. Varieties of functional deficits in prosopagnosia. Cereb. Cortex 2, 375-388.

Sergent, J., Ohta, S., MacDonald, B., 1992. Functional neuroanatomy of face and object processing. A positron emission tomography study. Brain 115, 15-36.

Simmons, W.K., Bellgowan, P.S., Martin, A., 2007. Measuring selectivity in fMRI data. Nat. Neurosci. 10, 4-5.

Sorger, B., Goebel, R., Schiltz, C., Rossion, B., 2007. Understanding the functional neuroanatomy of acquired prosopagnosia. NeuroImage 35 , 836-852.

Spiridon, M., Kanwisher, N., 2002. How distributed is visual category information in human occipito-temporal cortex? An fMRI study. Neuron $35,1157-1165$.

Steeves, J.K., Culham, J.C., Duchaine, B.C., Pratesi, C.C., Valyear, K.F., Schindler, I., Humphrey, G.K., Milner, A.D., Goodale, M.A., 2006. The fusiform face area is not sufficient for face recognition: evidence from a patient with dense prosopagnosia and no occipital face area. Neuropsychologia 44, 594-609.

Talairach, G., Tournoux, P., 1988. Co-Planar Stereotaxic Atlas of the Human Brain. Thieme Verlag, New York.

Tanaka, K., Saito, H., Fukada, Y., Moriya, M., 1991. Coding visual images of objects in the inferotemporal cortex of the macaque monkey. J. Neurophysiol. 66, 170-189.

Tovee, M.J., 1998. Face processing: getting by with a little help from its friends. Curr. Biol. 8, R317-R320.

Tsao, D.Y., Freiwald, W.A., Tootell, R.B., Livingstone, M.S., 2006. A cortical region consisting entirely of face-selective cells. Science 311 , 670-674.

Warrington, E. K. (1984). Recognition memory test (Windsor NFERNELSON).

Winston, J.S., Henson, R.N., Fine-Goulden, M.R., Dolan, R.J., 2004. fMRIadaptation reveals dissociable neural representations of identity and expression in face perception. J. Neurophysiol. 1830-1839. 